\title{
The Cost-Effectiveness of HIV/STI Prevention in High-Income Countries with Concentrated Epidemic Settings: A Scoping Review
}

\author{
Palmo Brunner ${ }^{1} \cdot$ Karma Brunner $^{1} \cdot$ Daniel Kübler $^{1}$ (D
}

Accepted: 8 January 2022 / Published online: 15 January 2022

(c) The Author(s) 2022

\begin{abstract}
The purpose of this scoping review is to establish the state of the art on economic evaluations in the field of HIV/STI prevention in high-income countries with concentrated epidemic settings and to assess what we know about the cost-effectiveness of different measures. We reviewed economic evaluations of HIV/STI prevention measures published in the Web of Science and Cost-Effectiveness Registry databases. We included a total of 157 studies focusing on structural, behavioural, and biomedical interventions, covering a variety of contexts, target populations and approaches. The majority of studies are based on mathematical modelling and demonstrate that the preventive measures under scrutiny are cost-effective. Interventions targeted at high-risk populations yield the most favourable results. The generalisability and transferability of the study results are limited due to the heterogeneity of the populations, settings and methods involved. Furthermore, the results depend heavily on modelling assumptions. Since evidence is unequally distributed, we discuss implications for future research.
\end{abstract}

Keywords HIV/STI prevention · Economic evaluations · Scoping review

\section{Resumen}

El objetivo de esta revisión de alcance ("scoping review") es exeminar las investigaciones realizadas acerca de las evaluaciones económicas en el campo de la prevención del VIH/ITS en países de altos ingresos con epidemia concentrada y evaluar actuales conocimientos sobre las relaciones costoeficacia de las diferentes medidas. Con este objetivo han sido revi-sadas las evaluaciones económicas de las medidas de prevención del VIH/ITS publicadas en las bases de datos Web of Science y Cost- Effectiveness Registry. Incluidos fueron 157 estudios sobre intervenciones estructurales, conductuales y biomédicas que abarcan una variedad de contextos, poblaciones objetivo y enfoques. La mayoría de los estudios se basan en modelos matemáticos y demuestran que las medidas preventivas analizadas son costo-efectivas. Las intervenciones dirigidas a poblaciones de alto riesgo han mostrado los resultados más favorables. La generalizabilidad y transferibilidad de los hallazgos son limitadas debido a la heterogeneidad de las poblaciones, los escenarios y de los métodos utilizados. Además, los resultados dependen en gran medida de las hipótesis de modelización. Dado que las pruebas están distribuidas de forma desigual, se discuten las implicaciones para una futura investigación.

Palabras clave Prevención del VIH/ITS · evaluaciones económicas · revision de alcance

\section{Introduction}

Sexually transmitted infections (STIs), and HIV in particular, are a significant public health issue. Effective prevention is critical to ending the HIV epidemic and combatting

Daniel Kübler

Daniel.Kuebler@ipz.uzh.ch

1 Department of Political Science, University of Zurich, Affolternstrasse 56, 8050 Zurich, Switzerland
STIs. Evidence on the cost-effectiveness of prevention interventions and programmes is vital: In the context of limited resources, policy-makers need to balance the costs and benefits of preventive interventions [1].

Economic evaluations are important to decision-making. By quantifying and comparing the costs and outcomes of different interventions, they help to identify measures that offer the best value for money [2]. Evidence on cost-effectiveness is essential not only for priority setting [3], but also for the successful implementation of programmes [4]. However, 
the high number of economic evaluations (such as costeffectiveness, cost-utility, or cost-benefit studies) makes it hard for decision-makers to maintain a broad perspective. A bibliometric analysis conducted in 2019 identified 372 economic evaluations in the field of HIV/AIDS alone, and highlighted various discrepancies in the existing evidence, as well as geographical and methodological heterogeneity [5].

Therefore, we aim to support decision-making by examining the 'extent, range and nature' of research activity $[6$, 7]. A scoping review is a useful and increasingly popular approach to map the evidence available in broad fields [8, 9]. The objective of the present scoping review is twofold: (1) to summarise the evidence on the cost-effectiveness of different interventions in the field of HIV/STI prevention to identify the most promising measures; and (2) to map the research field and identify potential shortcomings as well as research gaps.

\section{Methods}

We performed this scoping review following the guidelines of the Preferred Reporting Items for Systematic Reviews and Meta-Analyses (PRISMA) Statement to systematically identify relevant studies (see research protocol, S1). An advisory group accompanied the process to ensure relevance for policy-making.

\section{Search Strategy and Inclusion Criteria}

In May and June 2019, we electronically searched the Web of Science (WoS) and the Cost-Effectiveness Analysis (CEA) Registry. Tailored to the requirements of each database, the search strategy was based on the following three concepts: (1) HIV and/or STI; (2) preventive interventions; and (3) economic evaluation. For WoS, we used the following search algorithm:

(HIV OR HIV/AIDS OR AIDS OR HIV/STI OR STI OR HIV/STD OR STD) AND prevent* AND (cost* OR spend*) AND (effective* OR consequence* OR utilit* OR benefit* OR efficiency OR (economic AND evaluation))

For the CEA registry, only a basic search option was available. Therefore, we entered the different types of STIs separately and checked all entries for studies according to predefined inclusion criteria.

We formulated the inclusion criteria according to PICO (population, intervention, comparison, and outcome) guidelines. We included economic evaluations of preventive interventions or programmes targeting the general population, risk groups, or infected persons. We included any research designs of full economic evaluations-such as cost-benefit analysis (CBA), cost-effectiveness analysis (CEA), or costutility analysis (CUA) — if based on a comparison between different interventions or on/off comparisons. We did not predefine outcomes of HIV/STI prevention a priori and included measures such as averted infections, behavioural changes, and quality adjusted life years (QALYs). We only included studies focusing on Western, high-income democratic countries with concentrated epidemic settings in order to have a comparable context, not only with respect to the policy resources available, but also with regard to transmission patterns. Further, we only considered studies conducted after 1998 and up until 30 June 2019. We chose the 1998 starting point since lifetime financial and utility costs of HIV infections dramatically changed after the introduction of effective antiretroviral therapy (ART). Finally, we only considered English language articles published in peerreviewed journals.

\section{Study Selection and Data Extraction}

We selected eligible publications using the multistep approach illustrated in Fig. 1. First, one author (PB) screened all titles and abstracts for eligibility. Then, full papers were obtained for those that appeared potentially relevant and were available. In the next step, the second author (KB) assessed the full text of each article and doublechecked for inclusion according to the predefined criteria. Ambiguous cases were discussed between $\mathrm{PB}$ and $\mathrm{KB}$, and the third author (DK) was consulted in cases of conflict or uncertainty.

The focus of the study was HIV/STI prevention but not treatment, and we only included studies related to treatment if explicitly researching treatment-based prevention. Furthermore, we excluded studies on the effectiveness of interventions that did not evaluate monetary aspects; nor did we consider economic evaluations containing only a cost description but not assessing the effects. Last, we excluded studies based on data collected mainly before the introduction of effective ART regimens, resulting in the exclusion of studies published earlier than 2000.

For all included publications, we abstracted the following data: formal criteria, focus of the study, target group, intervention, outcome, study design, and relevant details regarding cost effectiveness. Cost-effectiveness indicates a society's willingness to pay for health gains and thus depends on the unique local aspects of the specific intervention being evaluated. Consequently, we did not use a common threshold to assess cost-effectiveness, but rather reported cost-effectiveness results based on the main findings of the included articles. Further, we refrained from assessing the quality of the methods applied, since the diversity in methodology, assumptions, and models used to estimate the outcomes across studies and interventions makes it difficult to establish 

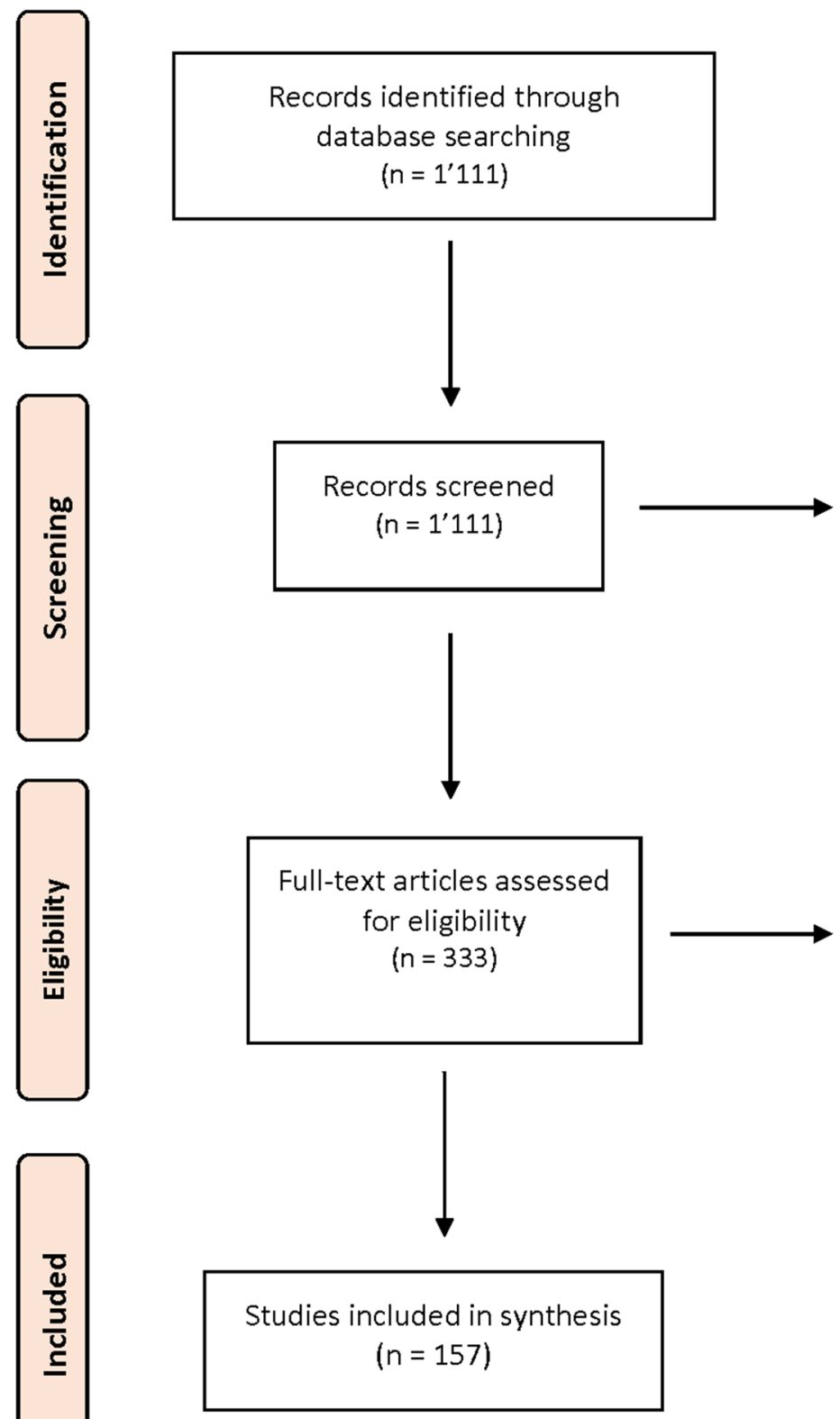

\section{Records excluded}

$(n=778)$

Incl. duplicates within database removed $=5$

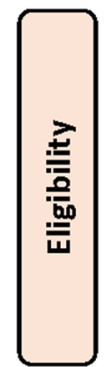

웡

Fig. 1 Selection of included studies based on the PRISMA flow diagram

quality. However, we reported whether sensitivity analysis was performed and whether limitations were addressed. In addition, we noted whether funding details were disclosed.

Data were abstracted by one author (KB) using a standardised form based on a codebook developed, tested, piloted and refined by all authors, together with the members of the advisory group (see S2). A second author (PB) independently checked the data for consistency and clarity. Uncertainties in coding were discussed among all three authors. Since coding was done mainly by one author (KB), the reliability of coding was assessed as intracoder reliability: After completion of coding, ten studies were selected randomly and coded again by the same coder (KB). For these ten studies, Krippendorf's alpha for intracoder reliability was 0.882 , which is clearly above the conventional minimal value of 0.61 .

\section{Results}

Our search in the two databases yielded a total of 1111 records from which we excluded 778 articles in the title and abstract screening process. Of the 333 remaining potentially relevant articles, we excluded 153 after full-text assessment. 
After removing 23 duplicates, we identified 157 relevant studies.

The subsequent review proceeded in two steps. First, we mapped the overall field regarding not only focus, type of preventive intervention, target population, and outcomes but also country region, year of publication, and other study characteristics. Second, we summarised the results of the studies for different intervention types separately, discussed the reported effects, and formed a narrative synthesis. (See S3 for an overview of all included studies.)

\section{Mapping the Field: Characteristics of the Included Studies}

The number of economic evaluations of interventions in the field of HIV/STI prevention has increased since 2000, with an average of eight publications per year, peaking at 16 publications in 2018. Papers appeared in a plethora of journals. Outlets with ten or more studies included AIDS, Sexually Transmitted Diseases, AIDS \& Behaviour and PLOS ONE. The prevalence of studies conducted in the North American context was striking (62\%), with most of them originating in the US (56\%). Thirteen percent of the studies had an international focus covering more than one country. Fewer economic evaluation studies on HIV/STI prevention have been conducted in Western European countries (20\%), whereby the UK (8\%) and the Netherlands (7\%) head the list.
Most studies entailed a form of mathematical modelling (82\%) including decision analytic models, threshold analyses, Markov and deterministic models, static and dynamic models, and individual- and population-based models. Systematic reviews were the second most frequent design (15\%). When deciding which types of costs and benefits to include in an economic evaluation, the most common were a societal perspective (33\%) and a health care system perspective (27\%). Most studies employed an annual discount rate of $3 \%$.

The main focus of the studies was HIV, and only 12 studies each were published on chlamydia and hepatitis B/C, whereby studies on gonorrhoea (3), syphilis (2), or STIs in general (6) were less common.

With respect to target groups (Fig. 2), the largest share of studies analysed interventions for more than one target group (25\%), followed by 30 papers focusing on men who have sex with men (MSM). The general public, youth, and pregnant women accounted for one-third of the studies. Many fewer studies, however, dealt with other risk groups such as injecting drug users (IDUs), prisoners, female sex workers (FSWs), or people living with HIV (PLWH) and their partners. Other targeted groups included mentally ill persons or older individuals.

Regarding interventions (Fig. 3), the largest share of studies focused on screening and/or testing as a preventive measure, and $10 \%$ of the included studies dealt with pre-exposure

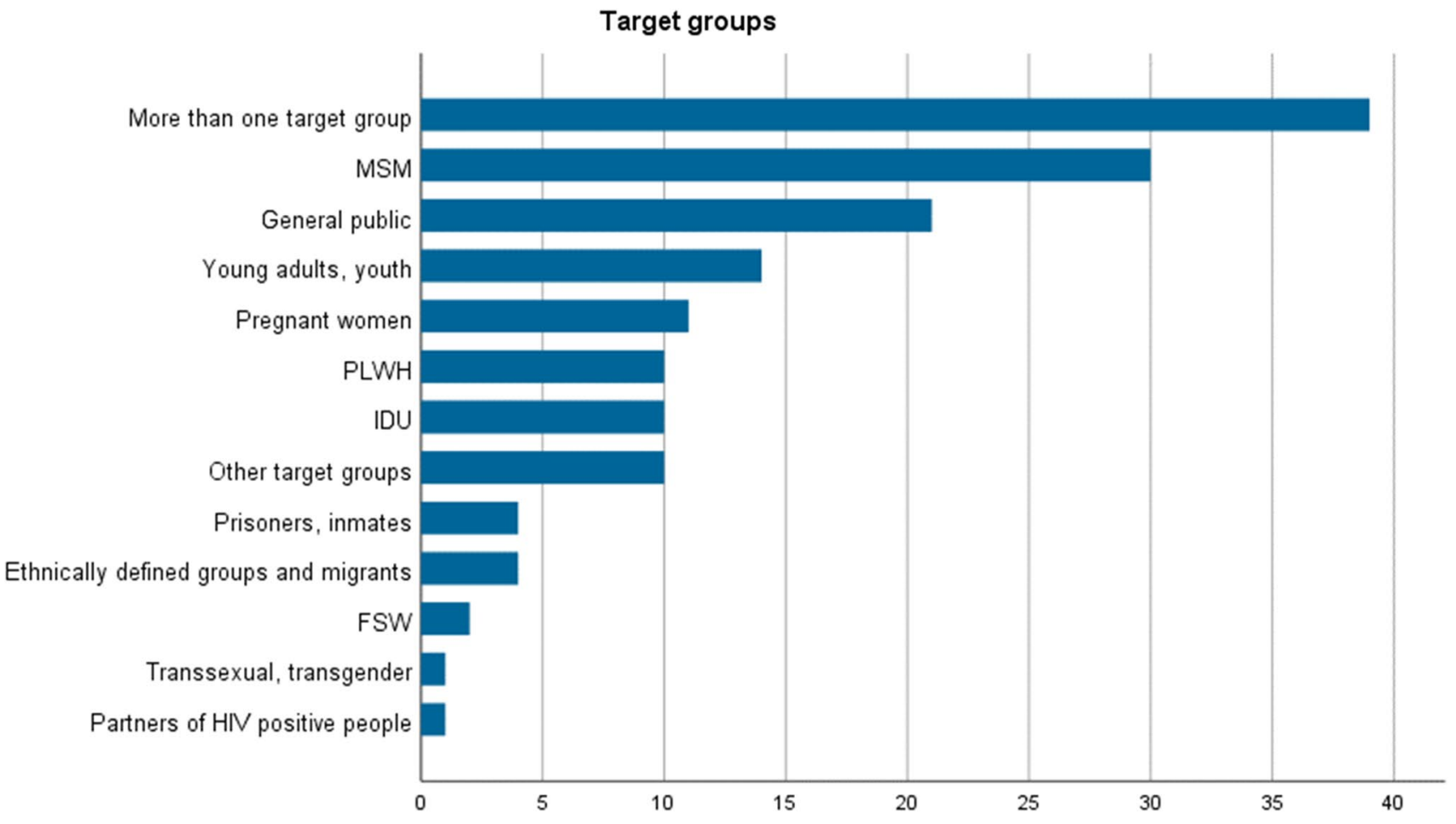

Fig. 2 Number of studies on different target groups 


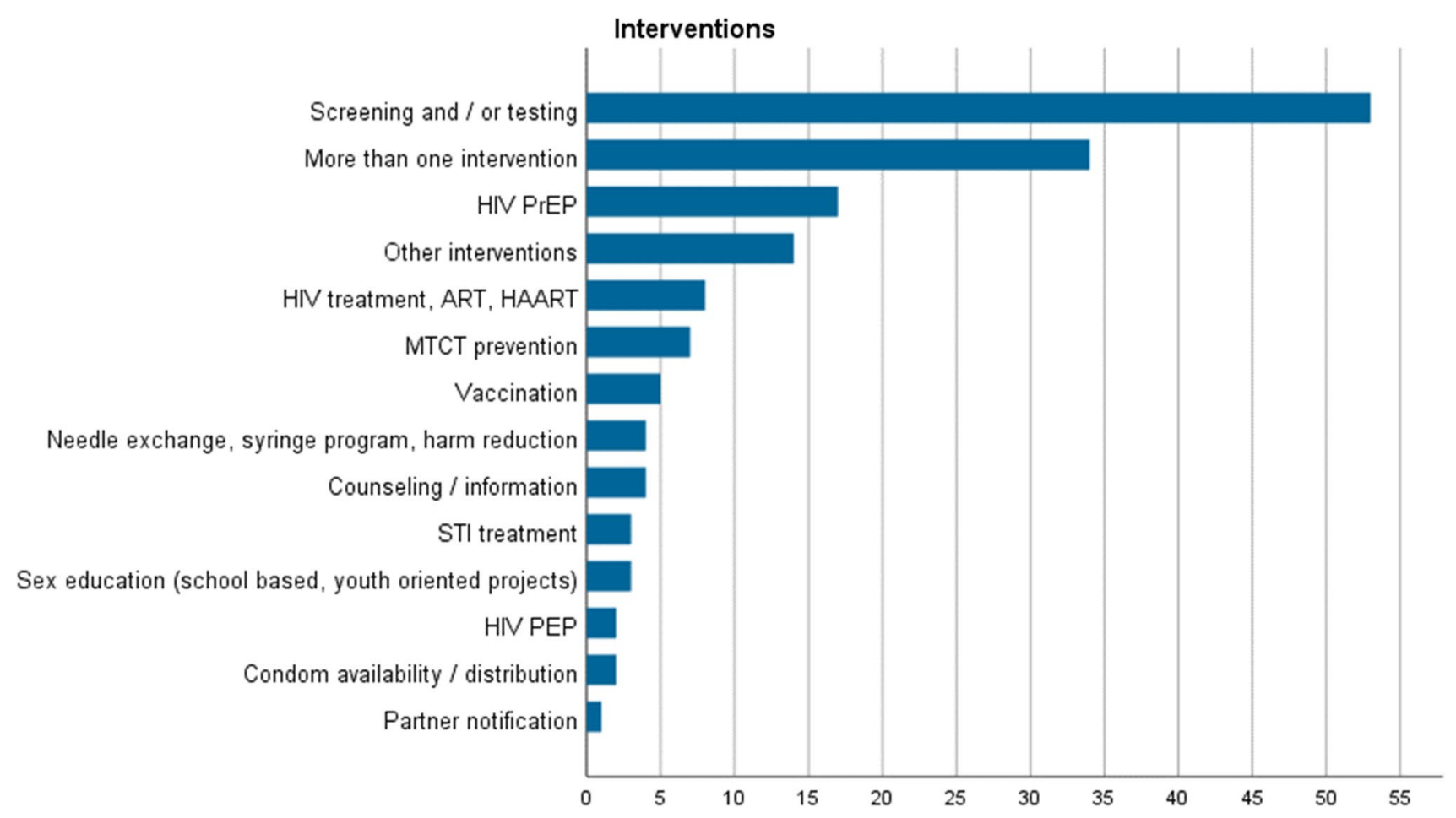

Fig. 3 Number of studies on different intervention types

prophylaxis (PrEP), i.e. medication taken to reduce the risk of HIV transmission via sex or injection drug use. A total of 34 studies analysed more than one intervention. In conclusion, there is substantially more scientific evidence on biomedical interventions than on structural approaches or measures aimed at behavioural changes. One possible explanation is that the effects of biomedical interventions are more straightforward to study but also include more recent approaches and developments.

One of our selection criteria was that a study estimated the cost per unit of effect for each intervention under scrutiny. The most commonly used outcome variable was the number of infections prevented (27\%), but measures such as the number of QALYs gained (12\%) or the averted costs of (future) treatment (7\%) were also used. However, a majority of studies included more than one indicator for outcome measurement (42\%). Here, again, methodological considerations might be decisive for measurement choice. Indeed, only $2 \%$ of the studies included in this review focused on a decrease in risky behaviour as a primary outcome variable, which is difficult to measure.

Looking at the chief conclusion of the included studies, only $4 \%$ reported that the intervention under examination was not cost-effective, whereas $6 \%$ did not explicitly give any assessment. Almost one-third (29\%) concluded that the evaluated interventions were cost-effective, and $6 \%$ found them to have been cost-saving. Forty-three percent concluded that the interventions assessed might be considered cost-effective and/or cost-saving under certain conditions (such as reduced drug prices) or reported more than one outcome (12\%). This finding comes as no surprise since a majority of the studies were based on mathematical modelling and therefore compared different scenarios. However, it is important to note that the reviewed papers used different definitions and thresholds of cost-effectiveness.

The majority of the studies contained an explicit discussion of potential biases and limitations and included sensitivity analyses. The source of funding was not disclosed in $45 \%$ of the studies (it was disclosed in $21 \%$ ), and $34 \%$ of the studies explicitly discussed the (non)involvement of the funding source.

\section{Findings on Different Prevention Interventions: Narrative Synthesis}

In the second step, we categorised the 157 studies into three main areas of HIV/STI prevention: (1) structural approaches; (2) interventions aiming at behavioural changes; and (3) biomedical interventions. Within these three categories, we made a further distinction between different subcategories in a narrative synthesis. We discuss studies covering several categories or subcategories of interventions according to their central emphasis. Additionally, we separately list measures to prevent mother-to-child transmission (MTCT). 
Finally, we assess studies comprising comparisons or combinations of different measures in the last section.

\section{Structural Approaches}

Structural interventions seek to address contextual aspects that facilitate or hinder the prevention of HIV or STI infections, such as socio-political, economic, or legal factors [10]. This approach therefore aims to prevent transmission by altering the environment, rather than by targeting risky behaviour [10]. Among the 157 studies included in this review, fifteen concentrated on structural approaches: three on broad national policies, four on needle exchange programmes, three on condom distribution, four on linkage and retention programmes for PWLH, and one compared different structural approaches. They show that these interventions not only reduce infection numbers, but also that they are cost-effective.

Broad Policy Initiatives and National Programmes Two studies evaluated broad national programmes in the US and found generally positive outcomes. The national gonorrhoea control programme for the general population was found to be cost-saving if the benefits of gonorrhoea prevention and other benefits were considered [11]. The authors of the study estimated that 32 million infections with gonorrhoea were averted over a 33-year period due to prevention measures including disease surveillance, clinical services, the provision of condoms, counselling and partner services, and the implementation of behavioural change interventions. Additionally, a study analysing a US capacity-building programme concluded that community-based organisations can meet cost-effectiveness thresholds given the lifetime treatment costs of HIV [12]. Last, in an economic evaluation of community-based HIV prevention programmes in Ontario, Canada - which included education, campaigns, and social support-programmes were found not only to reduce the number of HIV infections, but also to reduce health care costs [13].

Harm Reduction and Needle Exchange Four studies focused on needle-syringe exchange programmes (NSPs). A review established that NSPs reduce HIV transmission in intravenous drug users not only in an effective and safe way, but also in a cost-effective manner [14]. In a similar vein, an Australian study found that NSPs are likely to avert a substantial number of not only HIV, but also hepatitis $\mathrm{C}$ virus (HCV) infections among IDUs, and are thus cost-effective in the short term and even cost-saving when future health outcomes and costs are taken into account [15]. Concerning HCV, NSPs in the US were found to have little impact on HCV incidence and prevalence [16]; however, in a UK study, this intervention was considered highly cost-effective
(<GBP 20,000 per QALY saved) [17]. HCV transmission among IDUs also depends on how comprehensive a harm reduction model is and whether it is coupled with referral of IDUs to treatment [16].

Condom Distribution Condom distribution programmes are a structural-level intervention aiming to increase the availability of condoms and their use. Three studies focusing on condom distribution programmes suggested that such programmes are cost-effective. If targeted at young people [18] or if conducted at a community level [19], such programmes might even be cost-saving. The same applies to a condom distribution programme targeted at women that was combined with education [20].

Linkage and Retention Programmes The four studies assessing linkage to, re-engagement with, and retention in care programmes for people living with HIV were all conducted in the US and based on mathematical modelling: access to care [21], early linkage [22], and linkage of HIV-infected jail releases to community HIV care [23] were found to be cost-effective. HIV linkage and retention programmes are thus an efficient investment from a societal and payer perspective since the thresholds appear achievable [24].

Comparison of Structural Interventions One study comparing different structural interventions aiming to prevent HIV in women in the southern US found all of these to be costeffective compared with average lifetime HIV treatment costs [25]. Mass media campaigns, condom availability, and alcohol taxes prevented the largest numbers of HIV infections and were found to be cost-effective at less than 10,000 USD per infection prevented.

\section{Behavioural Interventions}

Behavioural strategies are defined as interventions seeking to motivate behavioural change. Most of them aim to reduce the risky behaviour of infected individuals or of those at risk of HIV/STI transmission. The results of the 18 studies in this category imply that behavioural interventions are costeffective and potentially cost-saving; they reduce the risk of HIV transmission, and the savings resulting from averted HIV infections far exceed the costs of the interventions.

Counselling The fifteen economic evaluations on counselling focused on interventions targeting PLWH (2), MSM (3), IDUs (4), FSWs (1), prisoners (1), mentally ill persons (2), and others (2). They show that counselling can be costeffective, especially if targeted at high-risk groups.

A study reported that clinical provider-led counselling for $P L W H$ was cost-effective in reducing sexual HIV transmission risk compared to other types (by specialists or mixed) 
[26]. Further, holistic and individually based behavioural interventions for HIV-positive MSM with uncontrolled virus could potentially be cost-saving because of improvements regarding adherence as well as psychosocial concerns [27].

Another counselling intervention to improve adherence to ART among MSM was found to be cost-effective; even though counselling produced only modest benefits in terms of prevention, it provided significant benefits for individual patients at an affordable cost [28]. A systematic review suggested that individual-level, group-level, and communitylevel HIV behavioural interventions are cost-effective in reducing HIV risk behaviours among MSM by reducing unprotected anal intercourse and increasing condom use [29]. Similarly, interventions targeting young gay men were found to be cost-effective, since the cost for averting one HIV infection is by far inferior to the lifetime medical costs of HIV disease, also when compared with other prevention strategies [30].

Threshold analyses of interventions with sexual and injection risk-reduction components targeted at $I D U s$ and their sexual partners in the US found these to be cost-effective or even cost-saving since they have the potential to save substantial economic resources by averting HIV-related expenses [31]. For women using drugs, a standard intervention (pre- and post-test counselling) combined with a 'well-women exam' (an additional breast and routine pelvic examination with cervical cytological testing) is cost-effective for preventing hepatitis $\mathrm{C}$ and gonorrhoea [32]. One study found that behavioural interventions were effective and cost-effective at reducing HIV incidence among both HIV-positive and other IDUs [33]. Similarly, a project conducted in four US cities led to modest changes in sexual risk behaviours of HIV-positive IDUs [34].

A brief behavioural intervention was found to reduce the incidence of HIV and STIs among FSWs in a cost-effective manner [35]. If ART is included in the model, an annual intervention strategy even results in net savings.

Other researchers have examined what thresholds of a single- and multi-session behavioural intervention targeting young imprisoned men (who will be released from jail) need to be achieved to be cost-effective; they found that costs are comparable with other HIV interventions and that the thresholds should be achievable [36].

Economic evaluations of behavioural interventions targeted at adults with (severe) mental illness contained mixed conclusions but highlighted gender differences, and thus the importance, of focusing on gender-specific issues when planning HIV prevention interventions. For instance, a small group intervention aimed at risk reduction in the US did not result in significant condom use uptake by men, but was slightly cost-effective if directed toward high-risk, sexually active women [37]. Similarly, while advocacy training was the most cost-effective way to reduce risky behaviour in men, only single-session one-on-one interventions were found to be a cost-saving intervention in women [38].

Last, other studies included a community-level intervention targeting women in low-income housing developments in different US cities, showing moderate cost-effectiveness in comparison with other HIV prevention programmes for at-risk women [39]. Finally, interventions were found to be usually more cost-effective if they were initiated early on in the epidemic [40].

School-Based Interventions An economic evaluation of school-based interventions to prevent sexual risk behaviour concluded that such interventions can be cost-effective, but that local factors such as programme costs, prevalence and incidence rates, as well as medical costs, may qualify this conclusion [41]. School-based behavioural interventions are likely to bring improvements in knowledge and increased self-efficacy depending on the quality of intervention providers, their enthusiasm and expertise, and a supportive school culture that recognises the individual sexual health needs of young people [42]. However, evidence suggests that the reduction of sexual risk behaviour and infection rates is only moderate [42], and that the effect of the intervention on sexual behavioural outcomes is uncertain [43].

\section{Biomedical Interventions}

The majority of the studies included in this review (101 of 157) focused on biomedical interventions to prevent the transmission of HIV or other STIs. These cover testing and screening for the general population and at-risk groups (56), treatment as prevention (9), a so-called 'test and treat' combination (5), vaccination (6), and the use of antiretroviral drugs by HIV-uninfected persons to reduce the risk of HIV transmission pre- and post-exposure (25).

Testing and Screening Early identification of HIV infections and other STIs is critical not only because of better treatment options, but also to reduce the transmission from infected individuals to others. However, a significant number of people are unaware, for example, of their HIV status [44]. Given the well-established clinical and public health benefits of early detection, it comes as no surprise that with 56 studies out of 157 included in this scoping review, the largest number were concerned with testing and screening strategies. Of those, three were systematic reviews; the others were based on mathematical modelling. The most common outcome measure was the estimated cost per QALY gained, and some studies reported the costs per averted or identified infection. The subsequent synthesis involves subcategories according to the target population of the assessed interventions: the general population (16) and young adults (9), populations at higher risk, including partners of PLWH 
(3), MSM (8) and other at-risk groups (10). The last subcategory encompasses studies comparing different testing strategies or target groups (10). In sum, the studies indicate that expanded HIV/STI screening leads to earlier access to treatment, which then results in a decrease in morbidity and mortality, as well as a reduction in the transmission of HIV/ STIs. Less is known, however, about whether reductions in risk behaviour occur among those tested. The debate of whom to test and how frequently remains controversial in the studies reviewed here. Nevertheless, they offer concurring evidence that repeated screenings of high-risk populations provide good value for money, and that one-time screenings of populations with a low prevalence of STIs might be a sound public health investment. Testing is highly effective, especially if diagnosis is followed by prompt linkage to medical care.

STI screening in the general population: Sixteen studies assessed testing and screening strategies of STIs for the general population. Twelve focused on HIV, three on chlamydia, and one on HCV. They tended to imply that universal screening strategies in the general population, although costly, can be cost-effective, especially when they involve community-based one-time routine testing or programmes in emergency departments (ED). Focusing on HIV screening measures in a European context, a Dutch study showed that universal HIV screening of patients attending an STI clinic in Amsterdam had an acceptable cost-effectiveness estimate [45]. The cost-effectiveness of routine HIV screening in Portugal compared to the current approach (targeted and on-demand screening) was evaluated in another study [46], which concluded that one-time HIV screening in the general population would be a cost-effective measure and repeated screening in higher-risk regions and subpopulations a justified option. A UK study assessed the trade-off between benefits of an early HIV diagnosis - resulting in a decrease in morbidity, mortality, further transmission, and costsand increased treatment costs [47]. The findings suggest that HIV screening in primary care settings is cost-effective in the UK in the medium term. In the US context, several studies focused on the impact of preventive interventions recommended in Centers for Disease Control (CDC) guidelines, including routine HIV counselling, testing, and referral for patients with an HIV prevalence of $\geq 1 \%$ [48]. The authors found that routine HIV screening programmes in health care settings would most likely also remain cost-effective at a lower HIV prevalence [48]. Other studies showed that onetime screening for the general population [49] and routine, voluntary HIV screening for all is cost-effective [50], with incremental cost-effectiveness ratios of USD 30,800/QALY (one-time screening), USD 32,300/QALY (screening every 5 years), and USD 55,500/QALY (screening every 3 years) [51]. Another study found that an expanded HIV testing policy would have a large impact on government budgets and concluded that providing care for newly identified cases is likewise crucial [52]. An opt-out HIV testing-i.e. testing without the need for risk assessment and counselling-in all health care encounters for persons aged 13 to 64 was assessed in another study [53], which reported that even though potentially thousands of new infections would be detected, targeted counselling and testing still led to better performance. In another publication, this opt-out rapid HIV screening strategy was compared with physician-induced diagnostic rapid HIV testing in an urban ED, showing the former to be more costly but at the same time identifying more HIV infections [54]. Other studies focusing on the specific context of EDs found that targeted HIV screening can be a cost-saving option since it increases quality-adjusted life expectancy [55]. A review of economic evaluations on HIV screening in emergency departments emphasised that although many studies report cost outcomes, it is difficult to compare results [56]. However, many studies in the abovementioned review indicated that HIV screening in ED-based programmes is a cost-effective strategy. With regard to other STIs, a study in France compared HCV universal screening to the current strategy of screening only individuals at high risk of infection and found the latter to be cost-effective from a societal perspective [57]. Studies focusing on chlamydia prevention assessed a range of interventions. One study suggested that programmes targeting venues that have access to men at high risk could be cost-effective since men often transmit chlamydia [58]. Another study showed that a community-based intervention in Sweden called 'Chlamydia Monday' - consisting of the provision of information and increased availability of testing, treatment and contact tracing — was cost-effective [59]. The last study focused on rectal chlamydia trachomatis screening as an add-on to female urogenital screening in STI clinics in Canada, and highlighted that selected and universal rectal screening are cost-effective compared to universal urogenital-only screening strategies [60].

Screening of young adults: Nine studies focused on screening young adults, mainly concerning chlamydia but also other STIs such as gonorrhoea, hepatitis B virus (HBV), $\mathrm{HCV}$, and syphilis. These studies focused on a variety of settings, which makes general conclusions difficult. One study indicated that screening young women for gonorrhoea in US urban EDs is cost-effective and, because of considerable prevalence in this patient group, could prevent substantial reproductive morbidity [61]. Another publication focused on a school-based STI screening programme and showed that a chlamydia screening programme was cost-effective and could even be cost-saving in some settings [62]. Comparing different screening approaches for chlamydia trachomatis, one study found that the most cost-effective strategies were annual screening in all young women and targeted semiannual screening for those with a history of infection [63]. In 
a similar vein, an economic evaluation of the National Chlamydia Screening Programme in England-which includes annual testing offered to men and women aged under 25 found that under accepted thresholds, the current programme is the most cost-effective strategy compared to alternative approaches [64]. The cost-effectiveness of different screening strategies for Dutch young adults was analysed in another study, which showed that screening every two years would be optimal [65]. In contrast, repeated screening of chlamydia in the Netherlands was found to be cost-effective only with a willingness to pay threshold of $>$ EUR 50,000 per QALY gained [66]. Similarly, a modelling study indicated that an opportunistic chlamydia screening programme was unlikely to be cost-effective in Ireland and too expensive to implement [67]. Last, a study in Scotland, where chlamydia is the most common STI, revealed that current chlamydia testing strategies, focusing on individuals with symptoms or at high risk, are not cost-effective [68]. A more restrictive testing strategy was assessed in the Netherlands, where syphilis and HIV tests for younger, heterosexual clients were limited in 2015 due to rising costs of care [69]. This policy resulted in only a slight decrease in detected infections and in savings of EUR 435,000 per QALY lost. Further, the authors found it would be cost-effective to offer tests for syphilis and HIV to first- and second-generation immigrants and to conduct HIV testing in case of a positive chlamydia or gonorrhoea diagnosis.

Testing in populations at higher risk: A total of 21 studies assessed screenings for individuals with higher risks of STI infection. Their results vary across settings and target groups. However, the evidence suggests that testing strategies targeted at specific populations at high risk of HIV/ STI infection are cost-effective. Three studies examined partner notification, i.e. preventing HIV transmission by notifying sexual partners of an HIV-positive person. In an analysis of partner notification programmes for Dutch MSM, researchers found that partner notification strategies can be expected to prevent new infections in an increasingly costeffective manner over time [70]. More particularly, this study considered online partner notification to be a useful tool to get individuals at high risk to test for HIV. In a US study, partner counselling and referral services were examined, concluding that programme costs of point-of-care rapid HIV testing varied substantially by location [71]. Another telephone-based partner notification approach of prevalent STIs would cost USD 4499 per DALY; thus, the implementation of selective screening with partner tracing is seen as a cost-effective intervention [72]. Eight studies focused on HIV/STI screening targeted at MSM, five in the US, two in the Netherlands, and one in the UK. In one of the Dutch studies, the authors assessed annual anorectal chlamydia screening among MSM in care at HIV treatment centres, and found this added screening to be cost-saving if only a limited proportion of men were not routinely screened [73]. In another Dutch study, testing strategies for the detection of anogenital gonorrhoea among MSM were analysed, and the authors found that a gram-stained smear for symptomatic MSM was a cost-effective option [74]. The UK study evaluated a 'recall for rescreening' strategy and showed that this approach of rescreening MSM diagnosed with an STI leads to high screening rates and detections of new infections [75]. In an urban US context, rectal screening of MSM for chlamydia and gonorrhoea was considered potentially costeffective if targeted at MSM at risk [76]. Moreover, syphilis screening among MSM is considered a cost-saving option to prevent HIV infections [77]. Three other US studies focused on HIV screening of MSM. The first recommended HIV testing in MSM with an influenza-like illness in addition to encouraging annual antibody screening [78]. Furthermore, one study reported that community-based acute HIV testing compared to HIV antibody testing alone is cost-effective in preventing new infections among at-risk MSM [79]. Last, the authors highlighted that HIV testing should reach a costsaving threshold if the programmes can reach undiagnosed PLWH; hence, programme cost utility could be maximised if strategies target MSM who are most likely to have undiagnosed HIV [80]. A study on screening strategies targeting transgender persons assessed the costs and effectiveness of rapid HIV testing services in New York City and San Francisco [81]. The authors found that even though the programmes had relatively high fixed costs and required a substantial investment, testing services provided to transgender individuals helped to identify a high proportion of new HIV diagnoses among the persons tested. However, there were differences in the average costs per infection detected between the two sites (USD 3563/USD 8284), which was explained in the proportion of previously undiagnosed HIV infection among those tested. Regarding soon-to-be-released prisoners, offering HIV counselling and testing is seen as a cost-saving prevention measure [82]. An Australian study on regular and mandatory screenings of sex workers found this testing strategy to not be cost-effective since the incidence and prevalence of STIs in this population are very low because of almost universal condom use [83]. Thus, the authors recommended that screening frequencies for sex workers be based on local STI epidemiology. Two studies on rapid testing in substance abuse treatment programmes showed that both on-site rapid HIV testing [84] and on-site rapid $\mathrm{HCV}$ testing [85] increase life expectancy in a costeffective manner (<USD 100,000/QALY gained). Last, three studies focused on testing strategies in migrants, especially those born in countries with high STI/HIV prevalence. A systematic overview of the cost-effectiveness of HIV testing strategies in migrant populations in the European Economic Area concluded that community-based rapid testing programmes potentially improve access to and uptake of 
testing [86]. HBV/HCV screening targeted at foreign-born migrants from low endemic countries was found to be a cost-effective measure to enhance early identification and treatment (<EUR 10,000/QALY gained) [87]. A UK study on enhanced HBV screening among migrant populations concluded that a 'one-time opt out case-finding approach' in primary care settings is very likely to be cost-effective (approximately GBP 20,000/QALY gained) [88]. A study on notifications of a new HIV diagnosis through a social network strategy among minority populations found costs to vary strongly across sites [89]. Finally, an assessment of increased spending for HIV counselling and rapid testing in high-risk communities in the US indicated favourable effects on public health benefits and cost savings to society [90].

Comparison of testing strategies and target groups: Ten studies compared different testing strategies. Semi-annual testing via fourth-generation immunoassay was found to prevent a greater number of infections and to be more economically efficient than annual nucleic acid amplification testing strategies of MSM and IDUs [91]. Comparing the cost-effectiveness of HIV screening in different settings, one study reported that testing MSM in STI clinics and screenings in EDs was more cost-effective than diagnosis based on clinical manifestations, since PLWH are identified at lessadvanced stages of HIV infection [92]. HIV testing for highrisk seronegative individuals (young and old MSM, IDUs) is a costly intervention, but might be cost-effective if applied to a large high-risk population [93]. Another study comparing targeted and routine testing strategies found that the former resulted in higher positivity rates, but that routine testing led to a higher overall number of infections detected, concluding that a combined testing strategy is preferable [94]. The cost of identifying a new HIV diagnosis is, however, substantially higher in an outreach setting than in a clinical setting [95]. Evaluating three testing strategies, such as rapid HIV testing in clinical settings, community-based organisation (CBO) settings, and the Partner Notification Services programme, another study found that expanded testing programmes are cost-saving overall [96]. Regarding the frequency of testing, the CDC guidelines (a one-time test for low-risk individuals and annual testing for those at high risk) were considered too conservative by one study, whose authors advocated for more frequent testing as a cost-effective measure for all risk groups [97]. An assessment of the frequency of screening for different at-risk groups found quarterly HIV testing in MSM to be more cost-effective than annual testing, but more frequent than annual testing for IDUs to be not cost-effective [98]. In the UK, annual HIV testing of at-risk populations was found to be very cost-effective, and the identification of undiagnosed PLWH could be improved through additional one-time testing of all other adults [99]. A comparison of HCV screening strategies for different target groups in the Netherlands [100] revealed that a strategy aimed at the general population was not cost-effective, but a strategy accompanied by additional primary care support, as well as strategies targeting hard drug users, were cost-effective.

Treatment as Prevention (TasP) The treatment as prevention (TasP) strategy has gained importance and is seen as a winwin strategy not only due to individual health but also public health benefits [101]. Studies in this category not only support the potential of TasP to reduce the number of new HIV infections but also the economic benefits, despite its high costs.

Nine studies had an international focus and discussed the importance of TasP for the global goal of ending AIDS, whereby a further scale-up of treatment could produce greater economic benefits despite the high costs [102]. However, although TasP might be cost-effective, determining factors vary across settings [103], and its implementation strongly depends on governments being able to afford the costs [104], stressing the potential of generic drugs. Cost implications as well as effectiveness data from different settings were reviewed in a study that found that TasP strategies rely on complementary interventions to reduce new HIV infections [105]. One of these is providing access to care and ART to PLWH who do not have health insurance, the main goal of the US AIDS Drug Assistance Program, which was found to be cost-effective [106]. Similarly, studies in Canada indicated that an ART expansion scenario was associated with net benefits [107] and that ART scale-up has decreased HIV-related morbidity, mortality, and transmission and thus is cost-saving from a societal perspective [108].

Last, one study was concerned with HCV infection therapy for HIV-infected MSM in the Netherlands and concluded that treatment with direct-acting antivirals is crucial to preventing new infections since cured individuals cannot transmit HCV [109].

Combination: Test and Treat Five studies focused on a combination of testing and treatment strategies. A US study on HCB found that an inclusive approach encompassing screening and treating or vaccinating was cost-effective for different high-risk, high-prevalence populations [110]. Focusing on HIV-positive women, who have a high incidence of Trichomonas infections, screening and treatment for the purpose of decreasing HIV transmission to male partners was found to be cost-saving [111].

From a societal angle, an expansion of HIV screening and treatment is cost-effective: A combination of those approaches in the US could prevent $17 \%$ of infections and cost USD 21,580/QALY gained, even though changes in risk behaviour are also necessary to reduce the HIV epidemic significantly [112]. Likewise, another study found HIV testing and interventions used to foster treatment initiation to be cost-effective in contrast to ART retention initiatives [113]. 
Preventive measures target the various stages of the HIV care sequence; however, there are still substantial gaps in knowledge regarding how to maximise the value of health spending [114].

Vaccination The development of an effective vaccine is often seen as the holy grail of preventing HIV/STIs [115]. Six studies included in this scoping review assessed the effects of hypothetical vaccinations. They indicated possible benefits even of modestly effective vaccines, especially when vaccination is targeted at high-risk groups.

Looking at an adult population in STI clinics, one study found that substituting hepatitis A/B for hepatitis B vaccines would reduce morbidity and mortality in a cost-effective manner [116]. With regard to HCV, even a moderately effective vaccine is seen as cost-saving in high-risk groups and economically attractive in lower-risk cohorts [117]. An effective chlamydia vaccine for young women would also be cost-effective in the US [118].

With regard to HIV, one study suggested that HIV chemoprophylaxis among high-risk MSM could prevent a significant number of HIV infections and be cost-effective [119]. Similarly, some studies assumed that partially effective vaccines for at-risk groups (MSM and IDUs) would result in net cost savings [120], and vaccination strategies could have a great impact on reducing new infections among MSM in Australia [115].

Pre- and Post-exposure Prophylaxis (PrEP and PEP) Preexposure prophylaxis (PrEP) refers to the use of antiretroviral medications in HIV-uninfected persons prior to HIV risk exposure. Since clinical trials, such as the PROUD in the UK [121] or the French/Canadian IPERGAY [122] studies, have shown a high efficacy of this preventive intervention, it is considered to have great potential to reduce populationlevel transmission. However, the high costs of PrEP have until recently been seen as the main barrier to its use. Hence, economic evaluations are crucial to determine whether, in what settings, and for which populations this rather new prevention strategy is a worthy investment.

Among the studies included in this review, 23 focused on the cost-effectiveness of PrEP. Eleven studies were conducted in the US, some had an internationally comparative focus or were European (one each in the Netherlands, the UK, France, and Germany), two were carried out in Canada [123, 124], and one in Australia [125]. With 14, the majority of the PrEP studies focused on MSM, and some included the general population or specific target groups such as IDUs $[126,127]$ or serodiscordant heterosexual couples seeking to conceive [124, 128]. Most of the studies used some form of mathematical modelling, and four were reviews.

The studies generally acknowledged the high potential of PrEP for HIV prevention [129], especially in younger or high-risk populations [130]. Earlier studies were more sceptical from an economic angle due to the high costs and because they assumed a lower efficacy of PrEP [131]; recent studies, however, have found that PrEP can be cost-effective [123]. Some authors have even suggested that under certain conditions, most notably when drug prices are reduced, PrEP is cost-saving [132-134].

Offering PrEP to specific subgroups and for periods when a person is at particularly high risk, such as an event-based PrEP programme [135], helps to increase cost-effectiveness. Another study predicted that costs could be reduced the most if any of the non-daily regimens (PrEP on demand) were implemented [136]. However, the identification and successful targeting of most at-risk groups is not always straightforward. One study found that targeting HIV-negative MSM in a discordant regular partnership is the most cost-effective intervention, even though this highly targeted strategy would not have a large population-level impact [125]. In contrast, for serodiscordant heterosexual couples seeking to conceive, condomless sex restricted to time of ovulation is the most cost-effective strategy [124], but PrEP is only cost-effective if HIV suppression is low [128].

Findings of economic evaluations on PrEP depend heavily on underlying assumptions about HIV transmission (sexual behaviour, adherence), as well as about costs of drugs and other contextual factors; this explains the varied results on cost-effectiveness [137]. The maximum benefit from PrEP results from its introduction in combination with other HIV prevention programmes, such as screening and immediate treatment of diagnosed infections [138], except for vaccines that, once available, would be more cost-effective than PrEP [139]. However, more research on the optimal combination of test/PrEP/treat is needed since high PrEP coverage with early ART is expected to provide the greatest benefit, but is also the most expensive strategy [140]. Additionally, some caution is necessary because the use of PrEP could potentially lead to decreased condom use, which could lead to an increase in infections with other STIs. On the other hand, PrEP programmes are seen as a good strategy to better screen and treat STIs. For instance, a French study found additional benefits associated with the introduction of PrEP, such as the treatment of other diseases and a reduction in secondary infections [141]. In sum, even though the cost-effectiveness results vary, it appears that PrEP can be a cost-effective addition to other HIV prevention programmes since it has the potential to prevent a substantial number of HIV infections and thus to mitigate the HIV epidemic [142]. Existing evidence suggests that the enormous upfront costs in providing PrEP should result in substantial economic benefits in the long term [143]. However, high current drug costs limit cost-effectiveness. Further, access to PrEP for the general population of at-risk groups would be very expensive. Hence, most studies propose prioritisation 
based on the self-reported risk behaviour [144] of those at highest risk of HIV exposure (between 10 and 30\% coverage). Many reviewed studies performed sensitivity analyses and discussed limitations. For instance, data on changes in sexual risk behaviour, as well as adherence among people taking PrEP, would need to be taken into account to accurately assess the cost-effectiveness of PrEP [125]. Likewise, more information on sexual activity or drug resistance would be important. In particular, the lack of evidence on behavioural responses to PrEP [138], as well as the effect of its introduction on alternative prevention approaches [145], warrants further investigation.

Only two studies focused on post-exposure prophylaxis $(P E P)$, i.e. the use of antiretroviral medications in HIVuninfected persons after high-risk HIV exposure events. The two studies found that PEP was cost-saving for men who reported receptive anal intercourse (RAI), especially with an HIV-infected partner [146], and possibly cost-effective for injection-drug exposure and women reporting RAI [147].

\section{Mother-to-Child Transmission (MTCT)}

MTCT represents the major route of HIV infection for children. Twelve of the 157 included studies fell under this category. They show that universal screening of pregnant women for HIV and other STIs, such as chlamydia and syphilis, is a cost-effective measure to prevent MTCT. Both antenatal HIV screening and later rescreening are described as cost-effective or even cost-saving [148]. Studies suggest maximising screening coverage [149], even in cases of an extremely low HIV prevalence of $0.01 \%$ [150]. However, in certain settings where universal screening is not feasible, targeted rescreening of women with a history of high risks could be a valuable option. Moreover, prevention of MTCT is cost-effective if combined with drug treatment [32] or for women without prior prenatal care [151]. For a high-risk population of incarcerated pregnant women, routine prenatal screening is expected to significantly reduce MTCT [152]. Additionally, programmes that optimise adherence to treatment during pregnancy have the potential to diminish MTCT in a highly cost-effective manner [153]. Last, two studies reported that an elective caesarean section for HIVpositive women is considered a cost-effective intervention to prevent MTCT [154, 155], and for women with detectable HIV during pregnancy, it is associated with increased quality-adjusted life expectancy and lower costs compared with vaginal delivery. However, more recent evidence implies that for pregnant women with undetectable viral load under ART, vaginal delivery can be safe if breastfeeding is avoided [156].

Apart from HIV, MTCT involves other STIs. In an Australian study, researchers found that because of the increasing prevalence, screening of all young pregnant women for chlamydia was likely to be cost-effective compared with no screening or selective screening [157]. Further, two US studies focused on testing and screening pregnant women for STIs. The first determined, with the help of a decision analysis, the costs and benefits of screening young pregnant women for chlamydia trachomatis infections [158]. Considering a high prevalence ( $>17 \%)$, prenatal screening is cost-saving, and with the current prevalence rates (7\%), prenatal screening results in higher spending but also in a significant reduction in the morbidity of woman-infant pairs. In another publication, screening for syphilis was studied, showing more favourable results regarding cost-effectiveness as well as maternal and neonatal outcomes for repeated (versus single) screening strategies [159].

\section{Comparisons and Combinations of Different Interventions}

Even though economic evaluations on specific measures are valuable for policy-makers, a comparison of interventions or the effects of combinations of different measures can help to maximise the impact of their HIV prevention resources. Thus, comparing estimates of the cost-effectiveness of HIV interventions provides important insights regarding prioritisation. However, out of the eleven studies in this category, there were only two economic models and two reviews, which undertook a broad comparison among different prevention types. Seven studies compared interventions by focusing on specific populations.

Broad Comparisons In a wide-ranging study, the relative cost-effectiveness for 26 different HIV prevention interventions was estimated [160]. The authors found that in lowprevalence populations, the most cost-effective interventions were structural interventions, and in high-prevalence populations, interventions aimed at behavioural change were fairly cost-effective. Showing educational videos in STI clinics and raising alcohol taxes were among the most cost-effective prevention measures, whereas school-based education was one of the least cost-effective measures [160]. Another study compared the cost-effectiveness of STI prevention interventions in the US targeting MSM, IDUs, and sexually active heterosexuals [161]. The main finding was that interventions for high-risk populations such as MSM were most cost-effective, as well as measures associated with the care continuum, whereas interventions centred on populations potentially at risk (versus those who could transmit HIV) were the least cost-effective [161].

In a systematic review on the four measures recommended by the US CDC (HIV testing, prevention with PLWH and their partners, condom distribution, and policy initiatives), researchers found that published evidence only indicates the cost-effectiveness of HIV testing [162]. A more recent review indicated that cost-effectiveness can be considered established 
for interventions such as TasP, PrEP, testing, condoms, circumcision, behavioural interventions, and the prevention of MTCT [163].

Comparing Interventions in Specific Populations The seven studies in this category revealed that combinations of interventions targeted at specific populations can be cost-effective, but that interventions for high-risk populations, such as MSM, are the most cost-effective. In contrast, for low-prevalence populations, the most cost-effective interventions were structural interventions, as they are generally cheaper.

Comparing different policy scenarios in the US, one study argued that an expansion of testing and prevention services for $P L W H$ would be not only cost-effective, but also necessary to achieve national goals, in addition to scaling up coverage of HIV care and treatment [164]. Given the growing number of older PLWH in high-income countries, age-appropriate strategies should be adopted, whereas testing and other prevention efforts, such as education and outreach, are needed for older adults [165].

Because IDUs have a high prevalence and incidence of $\mathrm{HCV}$ infections, a systematic review was performed focusing on the cost effectiveness of prevention, screening and treatment [166]. Many cost-effectiveness ratios were below USD 100,000/QALY gained. Evaluating different programmes for IDUs in the context of the opioid epidemic in the US, another study concluded that investments in combined prevention programmes could markedly lower the risk of HIV transmission and enhance health outcomes [167]. In contrast to PrEP, other approaches such as opioid agonist therapy, needle exchange, and test and treatment are considered cost-effective if implemented alone or in combination. Similarly, a UK study on IDUs found that a combination of outreach, testing and treatment of hepatitis $\mathrm{C}$ within drug treatment units presented a cost-effective option, with an estimated incremental cost of GBP 1029/QALY gained [168].

For imprisoned MSM, one publication reported different scenarios and found that a screening, treatment, and condom provision intervention could avert many STIs at low costs and would be cost-saving if it results in moderately higher condom use in sexual activity after being released from prison [169].

Last, a systematic review of economic evaluations of oneto-one interventions for young adults to reduce STIs, as well as unplanned pregnancies, concluded that most of the studies, typically concerning testing or counselling strategies, revealed either cost-effective or even cost-saving outcomes in some instances [170].

\section{Discussion}

This scoping review shows that economic evaluations of interventions in the field of STI/HIV prevention are commonly based on mathematical modelling analyses, are frequently conducted in a US context, focus primarily on HIV, often target MSM as the main risk group, and a substantial portion of the studies evaluate testing strategies. This evidence suggests that most of the prevention interventions under investigation were cost-effective; only a few publications reported measures to not be costeffective. Cost-effectiveness estimates, however, should be interpreted with caution given the heterogeneity of approaches. Moreover, cost-effectiveness thresholds are not always defined and differ significantly, for example, with a willingness-to-pay threshold of USD 150,000 per QALY gained reported in a US study [138], or EUR 20,000 per QALY in the Netherlands [133]. The results of economic evaluations further depend heavily on model assumptions, and input parameters vary widely across studies. Although we observed the increased use of a standardised economic evaluation methodology, especially in HIV prevention research, outcomes per type of intervention are not always assessed with standardised methods.

\section{Evidence Synthesis for Policy-Making}

Although the included studies were very heterogeneous, some conclusions and general trends can be discerned.

First, structural approaches, such as needle-syringe exchange and condom distribution programmes, are economically efficient. In low-prevalence populations, structural interventions are the most cost-effective measure.

Second, behavioural interventions focusing on counselling and aiming to reduce risk behaviour can be costeffective, especially if targeted toward high-risk groups such as IDUs or MSM. School-based interventions can be cost-effective, but the included studies found only a modest effect on sexual risk-taking behaviour or infection rates of such interventions.

Third, the substantial body of evidence on biomedical strategies supports the expansion of screening strategies, which would lead to a decrease in morbidity and mortality, as well as a reduction in the transmission of HIV/ STIs. Even though the debate of whom to test and how frequently remains contested, study results support repeated testing for high-risk groups and one-time screenings for low prevalence populations. PrEP appears to be a costeffective HIV prevention measure for high-risk individuals among the population of MSM, especially if a long time 
horizon is considered and if drug prices decline. Studies discussing treatment as prevention show it to be a crucial strategy in the field of HIV/STI prevention, leading not only to individual and public health gains, but also economic benefits.

\section{Limitations}

This study has several limitations. First, due to its broad perspective, our scoping review includes studies that are heterogeneous with regard to targeted groups, settings, outcomes, and interventions assessed. A drawback is that we were unable to conduct a meta-synthesis and compare effect sizes across studies. For instance, some studies differentiated between cost-effective and cost-saving interventions, whereas others did not. Since we did not use a common threshold of cost-effectiveness, it is difficult to generalise the results, as the definitions of cost-effectiveness varied substantially between papers. Second, due to the large number of studies included, we were not able to assess the quality of the individual studies in detail. This is not mandatory for a scoping review methodology [7]; however, assessing the quality of the original sources would enhance the validity of the findings. Mathematical modelling analyses, which account for the majority of the studies, depend mostly on secondary data. Last, this review was restricted to studies published in English, which may have caused bias in excluding articles written in other languages.

\section{Knowledge Gaps and Implications for Further Research}

This review allowed us to identify a number of weaknesses and research gaps.

An initial drawback is that the robustness of the costeffectiveness findings strongly depends on the assumptions and thus on the available data. For instance, behavioural outcomes are more difficult to measure, and baseline data are often missing. Moreover, data on the exact allocations of costs were not available in many publications, which is why it is difficult to compare results, as costs may vary significantly if measures are applied in contexts other than the ones studied.

Second, we must consider possible bias in the included studies. For instance, only a few studies reported interactions between different prevention strategies or discussed how their results have been used in weighing policy alternatives. It is also often unclear how they isolated the impact of a particular intervention under investigation. In addition, not all studies were transparent on potential conflicts of interest, which could be an issue, especially for biomedical interventions. For instance, six studies on PrEP (out of 23) reported no funding information.

Third, many studies found a positive cost-effectiveness ratio since the costs of measures are contrasted with the lifetime treatment costs of HIV, which are generally still very high. With the availability of generic drugs, however, this assessment may change in the future, possibly leading to less favourable cost-effectiveness ratios. Whether a specific intervention becomes more or less cost-effective therefore also depends on advancements in the medical treatment of STIs and HIV/AIDS. Another aspect is the discounting of future health benefits, whereby most studies discounted health benefits at the same rate as costs, i.e. at $3 \%$. Last, future economic evaluations should focus on the empirical assessment of programmes as focal aspects. Cross-study comparability could be enhanced by clearly reporting and reflecting on contextual and biological factors. This would also be vital regarding the transferability of the results from one setting to another.

An important gap in the literature, highlighted in earlier studies, concerns combinations of interventions, which are crucial in the field of HIV/STI prevention [163]. Costeffectiveness analyses of interventions at later stages of the sequence of HIV care, such as linkage and retention in HIV/AIDS care, were not examined much compared to testing strategies. Further, there is much more evidence on biomedical interventions than on structural approaches or on interventions aimed at behavioural change. In addition, interventions that focus on digital options are absent in the literature. In recent years, eHealth has become a critical topic, which opens up a promising research agenda for future economic evaluations. Last, services for specific populations have been understudied, such as transgender people, who have a very high burden of HIV [171], sex workers, or foreign-born migrants at higher risk. Although earlier reviews have pointed out that the field is very unbalanced and programmes for significant populations in the HIV epidemic have been understudied [1], there is still an unequal distribution regarding research evidence.

Supplementary Information The online version contains supplementary material available at https://doi.org/10.1007/s10461-022-03583-y.

Author Contributions All authors contributed to the study's conception and design. KB and PB performed the literature search, coding, and analysis. PB wrote the first draft of the manuscript. DK commented on previous versions and produced the final draft. All authors read and approved the final manuscript.

Funding Open access funding provided by University of Zurich. This study was funded by the Medical Services of the Canton of Zurich and the City of Zurich, Switzerland. The grant was received by DK, and PB's and KB's salaries were funded through this grant. Representatives of the funders were part of the project's advisory group alongside other experts and researchers. The funders had no role in the study design, 
data collection and analysis, decision to publish, or preparation of the manuscript.

Data Availability The database with literature coding can be obtained from the corresponding author.

Code Availability Not applicable.

\section{Declarations}

Conflict of interest The authors have no conflicts of interest to declare that are relevant to the content of this article.

Ethical Approval Not applicable.

Consent to Participate Not applicable.

Consent for Publication Not applicable.

Open Access This article is licensed under a Creative Commons Attribution 4.0 International License, which permits use, sharing, adaptation, distribution and reproduction in any medium or format, as long as you give appropriate credit to the original author(s) and the source, provide a link to the Creative Commons licence, and indicate if changes were made. The images or other third party material in this article are included in the article's Creative Commons licence, unless indicated otherwise in a credit line to the material. If material is not included in the article's Creative Commons licence and your intended use is not permitted by statutory regulation or exceeds the permitted use, you will need to obtain permission directly from the copyright holder. To view a copy of this licence, visit http://creativecommons.org/licenses/by/4.0/.

\section{References}

1. Holtgrave DR, Qualls NL, Graham JD. Economic evaluation of HIV prevention programs. Annu Rev Public Health. 1996;17:467-88.

2. Rudmik L, Drummond M. Health economic evaluation: important principles and methodology. Laryngoscope. 2013;123(6):1341-7.

3. Creese A, Floyd K, Alban A, Guinness L. Cost-effectiveness of HIV/AIDS interventions in Africa: a systematic review of the evidence. Lancet. 2002;359(9318):1635-42.

4. Galárraga O, Colchero MA, Wamai RG, Bertozzi SM. HIV prevention cost-effectiveness: a systematic review. BMC Public Health. 2009;9(Suppl 1):S5.

5. Tran BX, Nguyen LH, Turner HC, Nghiem S, Vu GT, Nguyen CT, et al. Economic evaluation studies in the field of HIV/ AIDS: bibliometric analysis on research development and scopes (GAPRESEARCH). BMC Health Serv Res. 2019;19(1):834.

6. Cacchione PZ. The evolving methodology of scoping revicews. Clin Nurs Research. 2016;25(2):115-9.

7. Arksey H, O'Malley L. Scoping studies: towards a methodological framework. Int J Soc Res Methodol. 2005;8(1):19-32.

8. Sucharew H, Macaluso M. Progress notes: methods for research evidence synthesis: the scoping review approach. J Hosp Med. 2019;14(7):416-8.

9. Pham MT, Rajić A, Greig JD, Sargeant JM, Papadopoulos A, McEwen SA. A scoping review of scoping reviews: advancing the approach and enhancing the consistency. Res Syn Meth. 2014;5(4):371-85.
10. Gupta GR, Parkhurst JO, Ogden JA, Aggleton P, Mahal A. Structural approaches to HIV prevention. Lancet. 2008;372(9640):764-75.

11. Chesson HW. Estimated effectiveness and cost-effectiveness of federally funded prevention efforts on gonorrhea rates in the United States, 1971-2003, under various assumptions about the impact of prevention funding. Sex Transm Dis. 2006;33(10 Suppl):S140-4.

12. Dauner KN, Oglesby WH, Richter DL, LaRose CM, Holtgrave DR. Cost savings threshold analysis of a capacity-building program for HIV prevention organizations. AIDS Educ Prev. 2008;20(3):265-74.

13. Choi SKY, Holtgrave DR, Bacon J, Kennedy R, Lush J, McGee $\mathrm{F}$, et al. Economic evaluation of community-based HIV prevention programs in Ontario: evidence of effectiveness in reducing HIV infections and health care costs. AIDS Behav. 2016;20(6):1143-56.

14. Wodak A, Cooney A. Effectiveness of sterile needle and syringe programmes. Int J Drug Policy. 2005;16:31-44.

15. Kwon JA, Anderson J, Kerr CC, Thein H-H, Zhang L, Iversen $\mathrm{J}$, et al. Estimating the cost-effectiveness of needle-syringe programs in Australia. AIDS. 2012;26(17):2201-10.

16. Pollack HA. Cost-effectiveness of harm reduction in preventing hepatitis $\mathrm{C}$ among injection drug users. Med Decis Making. 2001;21(5):357-67.

17. Sweeney S, Ward Z, Platt L, Guinness L, Hickman M, Hope V, et al. Evaluating the cost-effectiveness of existing needle and syringe programmes in preventing hepatitis $\mathrm{C}$ transmission in people who inject drugs. Addiction. 2019;114(3):560-70.

18. Sadler S, Tosh J, Pennington R, Rawdin A, Squires H, Romero $\mathrm{C}$, et al. A cost-effectiveness analysis of condom distribution programmes for the prevention of sexually transmitted infections in England. J Epidemiol Community Health. 2017;71(9):897-904.

19. Bedimo AL, Pinkerton SD, Cohen DA, Gray B, Farley TA. Condom distribution: a cost-utility analysis. Int J STD AIDS. 2002;13(6):384-92.

20. Holtgrave DR, Maulsby C, Kharfen M, Jia Y, Wu C, Opoku J, et al. Cost-utility analysis of a female condom promotion program in Washington. DC AIDS Behav. 2012;16(5):1115-20.

21. Maulsby C, Jain KM, Weir BW, Enobun B, Werner M, Riordan $\mathrm{M}$, et al. Cost-utility of access to care, a national HIV linkage, re-engagement and retention in care program. AIDS Behav. 2018;22(11):3734-41.

22. Gopalappa C, Farnham PG, Hutchinson AB, Sansom SL. Cost effectiveness of the national HIV/AIDS strategy goal of increasing linkage to care for HIV-infected persons. J Acquir Immune Defic Syndr. 2012;61(1):99-105.

23. Spaulding AC, Pinkerton SD, Superak H, Cunningham MJ, Resch S, Jordan AO, et al. Cost analysis of enhancing linkages to HIV care following jail: a cost-effective intervention. AIDS Behav. 2013;17(Suppl 2):S220-6.

24. Jain KM, Maulsby C, Brantley M, Kim JJ, Zulliger R, Riordan $\mathrm{M}$, et al. Cost and cost threshold analyses for 12 innovative US HIV linkage and retention in care programs. AIDS Care. 2016;28(9):1199-204.

25. Cohen DA, Wu S-Y, Farley TA. Structural interventions to prevent HIV/sexually transmitted disease: are they cost-effective for women in the southern United States? Sex Transm Dis. 2006;33(7 Suppl):S46-9.

26. Marseille E, Shade SB, Myers J, Morin S. The cost-effectiveness of HIV prevention interventions for HIV-infected patients seen in clinical settings. J Acquir Immune Defic Syndr. 2011;56(3):e87-94.

27. Safren SA, Perry NS, Blashill AJ, O'Cleirigh C, Mayer KH. The cost and intensity of behavioral interventions to promote HIV 
treatment for prevention among HIV-positive men who have sex with men. Arch Sex Behav. 2015;44(7):1833-41.

28. Zaric GS, Bayoumi AM, Brandeau ML, Owens DK. The costeffectiveness of counseling strategies to improve adherence to highly active antiretroviral therapy among men who have sex with men. Med Decis Making. 2008;28(3):359-76.

29. Herbst JH, Beeker C, Mathew A, McNally T, Passin WF, Kay LS, et al. The effectiveness of individual-, group-, and communitylevel HIV behavioral risk-reduction interventions for adult men who have sex with men: a systematic review. Am J Prev Med. 2007;32(4 Suppl):S38-67.

30. Kahn JG, Kegeles SM, Hays R, Beltzer N. Cost-effectiveness of the Mpowerment Project, a community-level intervention for young gay men. J Acquir Immune Defic Syndr. 2001;27(5):482-91.

31. Pinkerton SD, Holtgrave DR, DiFranceisco W, Semaan S, Coyle SL, Johnson-Masotti AP. Cost-threshold analyses of the National AIDS Demonstration Research HIV prevention interventions. AIDS. 2000;14(9):1257-68.

32. Ruger JP, Abdallah AB, Ng NY, Luekens C, Cottler L. Costeffectiveness of interventions to prevent HIV and STDs among women: a randomized controlled trial. AIDS Behav. 2014;18(10):1913-23.

33. Song DL, Altice FL, Copenhaver MM, Long EF. Cost-effectiveness analysis of brief and expanded evidence-based risk reduction interventions for HIV-infected people who inject drugs in the United States. PLoS ONE. 2015;10(2):e0116694.

34. Tuli K, Sansom S, Purcell DW, Metsch LR, Latkin CA, Gourevitch $\mathrm{MN}$, et al. Economic evaluation of an HIV prevention intervention for seropositive injection drug users. J Public Health Manag Pract. 2005;11(6):508-15.

35. Burgos JL, Gaebler JA, Strathdee SA, Lozada R, Staines H, Patterson TL. Cost-effectiveness of an intervention to reduce HIV/STI incidence and promote condom use among female sex workers in the Mexico-US border region. PLoS ONE. 2010;5(6):e11413.

36. Johnson AP, Macgowan RJ, Eldridge GD, Morrow KM, Sosman J, Zack B, et al. Cost and threshold analysis of an HIV/STI/ hepatitis prevention intervention for young men leaving prison: project START. AIDS Behav. 2013;17(8):2676-84.

37. Pinkerton SD, Johnson-Masotti AP, Otto-Salaj LL, Stevenson LY, Hoffmann RG. Cost-effectiveness of an HIV prevention intervention for mentally ill adults. Ment Health Serv Res. 2001;3(1):45-55.

38. Johnson-Masotti AP, Pinkerton SD, Kelly JA, Stevenson LY. Cost-effectiveness of an HIV risk reduction intervention for adults with severe mental illness. AIDS Care. 2000;12(3):321-32.

39. Johnson-Masotti AP, Pinkerton SD, Sikkema KJ, Kelly JA, Wagstaff DA. Cost-effectiveness of a community-level HIV risk reduction intervention for women living in low-income housing developments. J Prim Prev. 2005;26(4):345-62.

40. Chesson HW. Cost effectiveness of one to one STI prevention interventions. Sex Transm Infect. 2007;83(6):423-4.

41. Wang LY, Davis M, Robin L, Collins J, Coyle K, Baumler E. Economic evaluation of Safer Choices: a school-based human immunodeficiency virus, other sexually transmitted diseases, and pregnancy prevention program. Arch Pediatr Adolesc Med. 2000;154(10):1017-24.

42. Shepherd J, Kavanagh J, Picot J, Cooper K, Harden A, BarnettPage E, et al. The effectiveness and cost-effectiveness of behavioural interventions for the prevention of sexually transmitted infections in young people aged 13-19: a systematic review and economic evaluation. Health Technol Assess 2010; 14(7):1-206, iii-iv.
43. Cooper K, Shepherd J, Picot J, Jones J, Kavanagh J, Harden A, et al. An economic model of school-based behavioral interventions to prevent sexually transmitted infections. Int J Technol Assess Health Care. 2012;28(4):407-14.

44. Bert F, Gualano MR, Biancone P, Brescia V, Camussi E, Martorana M, et al. Cost-effectiveness of HIV screening in high-income countries: a systematic review. Health Policy. 2018;122(5):533-47.

45. Bos JM, Fennema JS, Postma MJ. Cost-effectiveness of HIV screening of patients attending clinics for sexually transmitted diseases in Amsterdam. AIDS. 2001;15(15):2031-6.

46. Yazdanpanah Y, Perelman J, DiLorenzo MA, Alves J, Barros $\mathrm{H}$, Mateus C, et al. Routine HIV screening in Portugal: clinical impact and cost-effectiveness. PLoS ONE. 2013;8(12):e84173.

47. Baggaley RF, Irvine MA, Leber W, Cambiano V, Figueroa J, McMullen $\mathrm{H}$, et al. Cost-effectiveness of screening for HIV in primary care: a health economics modelling analysis. Lancet HIV. 2017;4(10):e465-74.

48. Walensky RP, Weinstein MC, Kimmel AD, Seage GR, Losina E, Sax PE, et al. Routine human immunodeficiency virus testing: an economic evaluation of current guidelines. Am J Med. 2005;118(3):292-300.

49. Paltiel AD, Weinstein MC, Kimmel AD, Seage GR, Losina E, Zhang H, et al. Expanded screening for HIV in the United States-an analysis of cost-effectiveness. N Engl J Med. 2005;352(6):586-95.

50. Walensky RP, Freedberg KA, Weinstein MC, Paltiel AD. Costeffectiveness of HIV testing and treatment in the United States. Clin Infect Dis. 2007;45(Suppl 4):S248-54.

51. Paltiel AD, Walensky RP, Schackman BR, Seage GR, Mercincavage LM, Weinstein MC, et al. Expanded HIV screening in the United States: effect on clinical outcomes, HIV transmission, and costs. Ann Intern Med. 2006;145(11):797-806.

52. Martin EG, Paltiel AD, Walensky RP, Schackman BR. Expanded HIV screening in the United States: what will it cost government discretionary and entitlement programs? A budget impact analysis. Value Health. 2010;13(8):893-902.

53. Holtgrave DR. Costs and consequences of the US Centers for Disease Control and Prevention's recommendations for opt-out HIV testing. PLoS Med. 2007;4(6):e194.

54. Haukoos JS, Campbell JD, Conroy AA, Hopkins E, Bucossi MM, Sasson C, et al. Programmatic cost evaluation of nontargeted opt-out rapid HIV screening in the emergency department. PLoS ONE. 2013;8(12):e81565.

55. Dowdy DW, Rodriguez RM, Hare CB, Kaplan B. Cost-effectiveness of targeted human immunodeficiency virus screening in an urban emergency department. Acad Emerg Med. 2011;18(7):745-53.

56. Hsu J, Zinsou C, Parkhurst J, N'Dour M, Foyet L, Mueller DH. Comparative costs and cost-effectiveness of behavioural interventions as part of HIV prevention strategies. Health Policy Plan. 2013;28(1):20-9.

57. Deuffic-Burban S, Huneau A, Verleene A, Brouard C, Pillonel J, Le Strat Y, et al. Assessing the cost-effectiveness of hepatitis C screening strategies in France. J Hepatol. 2018;69(4):785-92.

58. Gift TL, Gaydos CA, Kent CK, Marrazzo JM, Rietmeijer CA, Schillinger JA, et al. The program cost and cost-effectiveness of screening men for Chlamydia to prevent pelvic inflammatory disease in women. Sex Transm Dis. 2008;35(11 Suppl):S66-75.

59. Deogan CL, Bocangel MKH, Wamala SP, Månsdotter AM. A cost-effectiveness analysis of the Chlamydia Monday-a community-based intervention to decrease the prevalence of chlamydia in Sweden. Scand J Public Health. 2010;38(2):141-50.

60. Thanh NX, Akpinar I, Gratrix J, Plitt S, Smyczek P, Read R, et al. Benefit of adjunct universal rectal screening for Chlamydia 
genital infections in women attending Canadian sexually transmitted infection clinics. Int J STD AIDS. 2017;28(13):1311-24.

61. Aledort JE, Hook EW, Weinstein MC, Goldie SJ. The cost effectiveness of gonorrhea screening in urban emergency departments. Sex Transm Dis. 2005;32(7):425-36.

62. Wang LY, Burstein GR, Cohen DA. An economic evaluation of a school-based sexually transmitted disease screening program. Sex Transm Dis. 2002;29(12):737-45.

63. Hu D, Hook EW, Goldie SJ. Screening for Chlamydia trachomatis in women 15 to 29 years of age: a cost-effectiveness analysis. Ann Intern Med. 2004;141(7):501-13.

64. Adams EJ, Turner KME, Edmunds WJ. The cost effectiveness of opportunistic chlamydia screening in England. Sex Transm Infect 2007; 83(4):267-74; discussion 274-5.

65. Vries R de, van Bergen JEAM, Jong-van den Berg LTW de, Postma MJ. Cost-utility of repeated screening for Chlamydia trachomatis. Value Health 2008; 11(2):272-4.

66. de Wit GA, Over EAB, Schmid BV, van Bergen JEAM, van den Broek IVF, van der Sande MAB, et al. Chlamydia screening is not cost-effective at low participation rates: evidence from a repeated register-based implementation study in The Netherlands. Sex Transm Infect. 2015;91(6):423-9.

67. Gillespie P, O’Neill C, Adams E, Turner K, O'Donovan D, Brugha R, et al. The cost and cost-effectiveness of opportunistic screening for Chlamydia trachomatis in Ireland. Sex Transm Infect. 2012;88(3):222-8.

68. Looker KJ, Wallace LA, Turner KME. Impact and cost-effectiveness of chlamydia testing in Scotland: a mathematical modelling study. Theor Biol Med Model. 2015;12:2.

69. Suijkerbuijk AWM, Over EAB, van Aar F, Götz HM, van Benthem BHB, Lugnér AK. Consequences of restricted STI testing for young heterosexuals in the Netherlands on test costs and QALY losses. Health Policy. 2018;122(2):198-203.

70. Nichols BE, Götz HM, van Gorp ECM, Verbon A, Rokx $\mathrm{C}$, Boucher $\mathrm{CAB}$, et al. Partner notification for reduction of HIV-1 transmission and related costs among men who have sex with men: a mathematical modeling study. PLoS ONE. 2015;10(11):e0142576.

71. Shrestha RK, Begley EB, Hutchinson AB, Sansom SL, Song B, Voorhees $\mathrm{K}$, et al. Costs and effectiveness of partner counseling and referral services with rapid testing for HIV in Colorado and Louisiana. United States Sex Transm Dis. 2009;36(10):637-41.

72. Rahman MM, Khan M, Gruber D. A low-cost partner notification strategy for the control of sexually transmitted diseases: a case study from Louisiana. Am J Public Health. 2015;105(8):1675-80.

73. Vriend HJ, Lugnér AK, Xiridou M, van der Schim Loeff MF, Prins M, de Vries HJC, et al. Sexually transmitted infections screening at HIV treatment centers for MSM can be cost-effective. AIDS. 2013;27(14):2281-90.

74. Zwart JM, Mangen M-JJ, Bartelsman M, van Rooijen MS, de Vries HJC, Xiridou M. Microscopic examination of Gramstained smears for anogenital gonorrhoea in men who have sex with men is cost-effective: evidence from a modelling study. Sex Transm Infect 2019; 95(1):13-20.

75. Harte D, Mercey D, Jarman J, Benn P. Is the recall of men who have sex with men (MSM) diagnosed as having bacterial sexually transmitted infections (STIs) for re-screening a feasible and effective strategy? Sex Transm Infect. 2011;87(7):577-82.

76. Chesson HW, Bernstein KT, Gift TL, Marcus JL, Pipkin S, Kent $\mathrm{CK}$. The cost-effectiveness of screening men who have sex with men for rectal chlamydial and gonococcal infection to prevent HIV Infection. Sex Transm Dis. 2013;40(5):366-71.

77. Chesson HW, Kidd S, Bernstein KT, Fanfair RN, Gift TL. The Cost-effectiveness of syphilis screening among men who have sex with men: an exploratory modeling analysis. Sex Transm Dis. 2016;43(7):429-32.

78. Juusola JL, Brandeau ML, Long EF, Owens DK, Bendavid E. The cost-effectiveness of symptom-based testing and routine screening for acute HIV infection in men who have sex with men in the USA. AIDS. 2011;25(14):1779-87.

79. Hoenigl M, Chaillon A, Mehta SR, Smith DM, Graff-Zivin J, Little SJ. Screening for acute HIV infection in community-based settings: cost-effectiveness and impact on transmissions. J Infect. 2016;73(5):476-84.

80. Zulliger R, Maulsby C, Solomon L, Baytop C, Orr A, Nasrullah M, et al. Cost-utility of HIV testing programs among men who have sex with men in the United States. AIDS Behav. 2017;21(3):619-25.

81. Shrestha RK, Sansom SL, Schulden JD, Song B, Smith LC, Ramirez R, et al. Costs and effectiveness of finding new HIV diagnoses by using rapid testing in transgender communities. AIDS Educ Prev. 2011;23(3 Suppl):49-57.

82. Varghese B, Peterman TA. Cost-effectiveness of HIV counseling and testing in US prisons. J Urban Health. 2001;78(2):304-12.

83. Wilson DP, Heymer K-J, Anderson J, O'Connor J, Harcourt C, Donovan B. Sex workers can be screened too often: a costeffectiveness analysis in Victoria, Australia. Sex Transm Infect. 2010;86(2):117-25.

84. Schackman BR, Metsch LR, Colfax GN, Leff JA, Wong A, Scott CA, et al. The cost-effectiveness of rapid HIV testing in substance abuse treatment: results of a randomized trial. Drug Alcohol Depend. 2013;128(1-2):90-7.

85. Schackman BR, Leff JA, Barter DM, DiLorenzo MA, Feaster DJ, Metsch LR, et al. Cost-effectiveness of rapid hepatitis C virus (HCV) testing and simultaneous rapid HCV and HIV testing in substance abuse treatment programs. Addiction. 2015;110(1):129-43.

86. Pottie K, Lotfi T, Kilzar L, Howeiss P, Rizk N, Akl EA, et al. The effectiveness and cost-effectiveness of screening for HIV in migrants in the EU/EEA: a systematic review. Int J Environ Res Public Health. 2018;15(8):1700.

87. Suijkerbuijk AWM, van Hoek AJ, Koopsen J, de Man RA, Mangen M-JJ, de Melker HE, et al. Cost-effectiveness of screening for chronic hepatitis $\mathrm{B}$ and $\mathrm{C}$ among migrant populations in a low endemic country. PLoS ONE 2018; 13(11):e0207037.

88. Martin NK, Vickerman P, Khakoo S, Ghosh A, Ramsay M, Hickman M, et al. Chronic hepatitis B virus case-finding in UK populations born abroad in intermediate or high endemicity countries: an economic evaluation. BMJ Open 2019; 9(6): 030183.

89. Shrestha RK, Sansom SL, Kimbrough L, Hutchinson AB, Daltry $\mathrm{D}$, Maldonado W, et al. Cost-effectiveness of using social networks to identify undiagnosed HIV infection among minority populations. J Public Health Manag Pract. 2010;16(5):457-64.

90. Holtgrave DR. The president's fiscal year 2007 initiative for human immunodeficiency virus counseling and testing expansion in the United States: a scenario analysis of its coverage, impact, and cost-effectiveness. J Public Health Manag Pract. 2007;13(3):239-43.

91. Long EF. HIV screening via fourth-generation immunoassay or nucleic acid amplification test in the United States: a costeffectiveness analysis. PLoS ONE. 2011;6(11):e27625.

92. Prabhu VS, Farnham PG, Hutchinson AB, Soorapanth S, Heffelfinger JD, Golden MR, et al. Cost-effectiveness of HIV screening in STD clinics, emergency departments, and inpatient units: a model-based analysis. PLoS ONE. 2011;6(5):e19936.

93. Heumann KS, Marx R, Lawrence SJ, Stump DL, Carroll DP, Hirozawa AM, et al. Cost-effectiveness of prevention referrals for high-risk HIV-negatives in San Francisco. AIDS Care. 2001;13(5):637-42. 
94. Castel AD, Choi S, Dor A, Skillicorn J, Peterson J, Rocha N, et al. Comparing cost-effectiveness of HIV testing strategies: targeted and routine testing in Washington, DC. PLoS ONE. 2015;10(10):e0139605.

95. Shrestha RK, Clark HA, Sansom SL, Song B, Buckendahl H, Calhoun CB, et al. Cost-effectiveness of finding new HIV diagnoses using rapid HIV testing in community-based organizations. Public Health Rep. 2008;123(Suppl 3):94-100.

96. Li XC, Kusi L, Marak T, Bertrand T, Chan PA, Galárraga O. The cost and cost-utility of three public health HIV case-finding strategies: evidence from Rhode Island, 2012-2014. AIDS Behav. 2018;22(11):3726-33.

97. Lucas A, Armbruster B. The cost-effectiveness of expanded HIV screening in the United States. AIDS. 2013;27(5):795-801.

98. Hutchinson AB, Farnham PG, Sansom SL, Yaylali E, Mermin $\mathrm{JH}$. Cost-effectiveness of frequent HIV testing of high-risk populations in the United States. J Acquir Immune Defic Syndr. 2016;71(3):323-30.

99. Long EF, Mandalia R, Mandalia S, Alistar SS, Beck EJ, Brandeau ML. Expanded HIV testing in low-prevalence, high-income countries: a cost-effectiveness analysis for the United Kingdom. PLoS ONE. 2014;9(4):e95735.

100. Helsper CW, Borkent-Raven BA, de Wit NJ, van Essen GA, Bonten MJM, Hoepelman AIM, et al. Cost-effectiveness of targeted screening for hepatitis $\mathrm{C}$ in The Netherlands. Epidemiol Infect. 2012;140(1):58-69.

101. Venkatesh KK, Lurie MN, Mayer KH. How HIV treatment could result in effective prevention. Future Virol. 2010;5(4):405-15.

102. Forsythe SS, McGreevey W, Whiteside A, Shah M, Cohen J, Hecht R, et al. Twenty years of antiretroviral therapy for people living with HIV: global costs, health achievements. Econ Benefits Health Aff (Millwood). 2019;38(7):1163-72.

103. Kahn JG, Marseille EA, Bennett R, Williams BG, Granich R. Cost-effectiveness of antiretroviral therapy for prevention. Curr HIV Res. 2011;9(6):405-15.

104. Ogbuagu O, Bruce RD. Reaching the unreached: treatment as prevention as a workable strategy to mitigate HIV and its consequences in high-risk groups. Curr HIV/AIDS Rep. 2014;11(4):505-12.

105. Wilson D, Fraser N. Who pays and why? Costs, effectiveness, and feasibility of HIV treatment as prevention. Clin Infect Dis. 2014;59(Suppl 1):S28-31.

106. Pinkerton SD, Kibicho JW, Galletly CL. Is the US AIDS drug assistance program cost-effective? AIDS Behav. 2013;17(1):1-4.

107. Johnston KM, Levy AR, Lima VD, Hogg RS, Tyndall MW, Gustafson P, et al. Expanding access to HAART: a costeffective approach for treating and preventing HIV. AIDS. 2010;24(12):1929-35.

108. Nosyk B, Min JE, Lima VD, Hogg RS, Montaner JSG. Costeffectiveness of population-level expansion of highly active antiretroviral treatment for HIV in British Columbia, Canada: a modelling study. Lancet HIV. 2015;2(9):e393-400.

109. Popping S, Hullegie SJ, Boerekamps A, Rijnders BJA, de Knegt RJ, Rockstroh JK, et al. Early treatment of acute hepatitis C infection is cost-effective in HIV-infected men-who-have-sexwith-men. PLoS ONE. 2019;14(1):e0210179.

110. Chahal HS, Peters MG, Harris AM, McCabe D, Volberding P, Kahn JG. Cost-effectiveness of Hepatitis B Virus Infection Screening and Treatment or Vaccination in 6 High-risk Populations in the United States. Open Forum Infect Dis. 2019;6(1):ofy353.

111. Lazenby GB, Unal ER, Andrews AL, Simpson K. Cost-effectiveness analysis of annual Trichomonas vaginalis screening and treatment in HIV-positive women to prevent HIV transmission. Sex Transm Dis. 2014;41(6):353-8.
112. Long EF, Brandeau ML, Owens DK. The cost-effectiveness and population outcomes of expanded HIV screening and antiretroviral treatment in the United States. Ann Intern Med. 2010;153(12):778-89.

113. Nosyk B, Min JE, Krebs E, Zang X, Compton M, Gustafson R, et al. The cost-effectiveness of human immunodeficiency virus testing and treatment engagement initiatives in British Columbia, Canada: 2011-2013. Clin Infect Dis. 2018;66(5):765-77.

114. Nosyk B, Krebs E, Eyawo O, Min JE, Barrios R, Montaner JSG. Cost-effectiveness analysis along the continuum of HIV care: how can we optimize the effect of HIV treatment as prevention programs? Curr HIV/AIDS Rep. 2014;11(4):468-78.

115. Gray RT, Ghaus MH, Hoare A, Wilson DP. Expected epidemiological impact of the introduction of a partially effective HIV vaccine among men who have sex with men in Australia. Vaccine. 2011;29(36):6125-9.

116. Jacobs RJ, Meyerhoff AS. Cost-effectiveness of hepatitis A/B vaccine versus hepatitis $B$ vaccine in public sexually transmitted disease clinics. Sex Transm Dis. 2003;30(11):859-65.

117. Krahn MD, John-Baptiste A, Yi Q, Doria A, Remis RS, Ritvo $\mathrm{P}$, et al. Potential cost-effectiveness of a preventive hepatitis $\mathrm{C}$ vaccine in high risk and average risk populations in Canada. Vaccine. 2005;23(13):1549-58.

118. Owusu-Edusei K, Chesson HW, Gift TL, Brunham RC, Bolan G. Cost-effectiveness of Chlamydia vaccination programs for young women. Emerging Infect Dis. 2015;21(6):960-8.

119. Desai K, Sansom SL, Ackers ML, Stewart SR, Hall HI, Hu DJ, et al. Modeling the impact of HIV chemoprophylaxis strategies among men who have sex with men in the United States: HIV infections prevented and cost-effectiveness. AIDS. 2008;22(14):1829-39.

120. Long EF, Owens DK. The cost-effectiveness of a modestly effective HIV vaccine in the United States. Vaccine. 2011;29(36):6113-24.

121. McCormack S, Dunn DT, Desai M, Dolling DI, Gafos M, Gilson $\mathrm{R}$, et al. Pre-exposure prophylaxis to prevent the acquisition of HIV-1 infection (PROUD): effectiveness results from the pilot phase of a pragmatic open-label randomised trial. The Lancet. 2016;387(10013):53-60.

122. Molina J-M, Capitant C, Spire B, Pialoux G, Cotte L, Charreau I, et al. On-demand preexposure prophylaxis in men at high risk for HIV-1 infection. N Engl J Med. 2015;373(23):2237-46.

123. Ouellet E, Durand M, Guertin JR, LeLorier J, Tremblay CL. Cost effectiveness of "on demand" HIV pre-exposure prophylaxis for non-injection drug-using men who have sex with men in Canada. Can J Infect Dis Med Microbiol. 2015;26(1):23-9.

124. Letchumanan M, Coyte PC, Loutfy M. An economic evaluation of conception strategies for heterosexual serodiscordant couples where the male partner is HIV-positive. Antivir Ther (Lond). 2015;20(6):613-21.

125. Schne K, Gray RT, Wilson DP. A cost-effectiveness analysis of HIV preexposure prophylaxis for men who have sex with men in Australia. Clin Infect Dis. 2014;58(7):1027-34.

126. Bernard CL, Brandeau ML, Humphreys K, Bendavid E, Holodniy $\mathrm{M}$, Weyant $\mathrm{C}$, et al. Cost-effectiveness of hiv preexposure prophylaxis for people who inject drugs in the United States. Ann Intern Med. 2016;165(1):10-9.

127. Fu R, Owens DK, Brandeau ML. Cost-effectiveness of alternative strategies for provision of HIV preexposure prophylaxis for people who inject drugs. AIDS. 2018;32(5):663-72.

128. Leech AA, Burgess JF, Sullivan M, Kuohung W, Horný M, Drainoni M-L, et al. Cost-effectiveness of preexposure prophylaxis for HIV prevention for conception in the United States. AIDS. 2018;32(18):2787-98.

129. Khurana N, Yaylali E, Farnham PG, Hicks KA, Allaire BT, Jacobson E, et al. Impact of Improved HIV Care and Treatment 
on PrEP Effectiveness in the United States, 2016-2020. J Acquir Immune Defic Syndr. 2018;78(4):399-405.

130. Paltiel AD, Freedberg KA, Scott CA, Schackman BR, Losina E, Wang B, et al. HIV preexposure prophylaxis in the United States: impact on lifetime infection risk, clinical outcomes, and cost-effectiveness. Clin Infect Dis. 2009;48(6):806-15.

131. Schackman BR, Eggman AA. Cost-effectiveness of pre-exposure prophylaxis for HIV: a review. Curr Opin HIV AIDS. 2012;7(6):587-92.

132. McKenney J, Chen A, Hoover KW, Kelly J, Dowdy D, Sharifi $\mathrm{P}$, et al. Optimal costs of HIV pre-exposure prophylaxis for men who have sex with men. PLoS ONE. 2017;12(6):e0178170.

133. Nichols BE, Boucher CAB, van der Valk M, Rijnders BJA, van de Vijver DAMC. Cost-effectiveness analysis of preexposure prophylaxis for HIV-1 prevention in the Netherlands: a mathematical modelling study. Lancet Infect Dis. 2016;16(12):1423-9.

134. Juusola JL, Brandeau ML, Owens DK, Bendavid E. The costeffectiveness of preexposure prophylaxis for HIV prevention in men who have sex with men in the United States. Ann Intern Med. 2012;156(8):541-50.

135. Cambiano V, Miners A, Dunn D, McCormack S, Ong KJ, Gill $\mathrm{ON}$, et al. Cost-effectiveness of pre-exposure prophylaxis for HIV prevention in men who have sex with men in the UK: a modelling study and health economic evaluation. Lancet Infect Dis. 2018;18(1):85-94.

136. Mitchell KM, Dimitrov D, Hughes JP, Xia F, Donnell D, Amico KR, et al. In what circumstances could nondaily preexposure prophylaxis for HIV substantially reduce program costs? AIDS. 2018;32(6):809-18.

137. Chen A, Dowdy DW. Clinical effectiveness and cost-effectiveness of HIV pre-exposure prophylaxis in men who have sex with men: risk calculators for real-world decision-making. PLoS ONE. 2014;9(10):e108742.

138. Drabo EF, Hay JW, Vardavas R, Wagner ZR, Sood N. A Costeffectiveness analysis of preexposure prophylaxis for the prevention of HIV among Los Angeles county men who have sex with men. Clin Infect Dis. 2016;63(11):1495-504.

139. Adamson BJS, Carlson JJ, Kublin JG, Garrison LP. The Potential cost-effectiveness of pre-exposure prophylaxis combined with HIV vaccines in the United States. Vaccines (Basel). 2017;5(2):13.

140. Shen M, Xiao Y, Rong L, Meyers LA, Bellan SE. The costeffectiveness of oral HIV pre-exposure prophylaxis and early antiretroviral therapy in the presence of drug resistance among men who have sex with men in San Francisco. BMC Med. 2018;16(1):58

141. Durand-Zaleski I, Mutuon P, Charreau I, Tremblay C, Rojas D, Pialoux G, et al. Costs and benefits of on-demand HIV preexposure prophylaxis in MSM. AIDS. 2018;32(1):95-102.

142. Hellinger FJ. Assessing the cost effectiveness of pre-exposure prophylaxis for HIV prevention in the US. Pharmacoeconomics. 2013;31(12):1091-104.

143. van de Vijver DAMC, Richter A-K, Boucher CAB, Gunsenheimer-Bartmeyer B, Kollan C, Nichols BE, et al. Costeffectiveness and budget effect of pre-exposure prophylaxis for HIV-1 prevention in Germany from 2018 to 2058. Euro Surveill. 2019;24(7):1800398.

144. Gomez GB, Borquez A, Case KK, Wheelock A, Vassall A, Hankins C. The cost and impact of scaling up preexposure prophylaxis for HIV prevention: a systematic review of cost-effectiveness modelling studies. PLoS Med. 2013;10(3):e1001401

145. Cambiano V, Miners A, Phillips A. What do we know about the cost-effectiveness of HIV preexposure prophylaxis, and is it affordable? Curr Opin HIV AIDS. 2016;11(1):56-66.
146. Herida M, Larsen C, Lot F, Laporte A, Desenclos J-C, Hamers FF. Cost-effectiveness of HIV post-exposure prophylaxis in France. AIDS. 2006;20(13):1753-61.

147. Pinkerton SD, Martin JN, Roland ME, Katz MH, Coates TJ, Kahn JO. Cost-effectiveness of postexposure prophylaxis after sexual or injection-drug exposure to human immunodeficiency virus. Arch Intern Med. 2004;164(1):46-54.

148. Sansom SL, Jamieson DJ, Farnham PG, Bulterys M, Fowler MG. Human immunodeficiency virus retesting during pregnancy: costs and effectiveness in preventing perinatal transmission. Obstet Gynecol. 2003;102(4):782-90.

149. Bert F, Gualano MR, Biancone P, Brescia V, Camussi E, Martorana $\mathrm{M}$, et al. HIV screening in pregnant women: A systematic review of cost-effectiveness studies. Int J Health Plann Manage. 2018;33(1):31-50.

150. Graves N, Walker DG, McDonald AM, Kaldor JM, Ziegler JB. Would universal antenatal screening for HIV infection be cost-effective in a setting of very low prevalence? Modelling the data for Australia. J Infect Dis. 2004;190(1):166-74.

151. Mrus JM, Tsevat J. Cost-effectiveness of interventions to reduce vertical HIV transmission from pregnant women who have not received prenatal care. Med Decis Making. 2004;24(1):30-9.

152. Resch S, Altice FL, Paltiel AD. Cost-effectiveness of HIV screening for incarcerated pregnant women. J Acquir Immune Defic Syndr. 2005;38(2):163-73.

153. McCabe CJ, Goldie SJ, Fisman DN. The cost-effectiveness of directly observed highly-active antiretroviral therapy in the third trimester in HIV-infected pregnant women. PLoS ONE. 2010;5(4):e10154.

154. Halpern MT, Read JS, Ganoczy DA, Harris DR. Cost-effectiveness of cesarean section delivery to prevent mother-to-child transmission of HIV-1. AIDS. 2000;14(6):691-700.

155. Mrus JM, Goldie SJ, Weinstein MC, Tsevat J. The costeffectiveness of elective Cesarean delivery for HIV-infected women with detectable HIV RNA during pregnancy. AIDS. 2000;14(16):2543-52.

156. Islam $\mathrm{S}$, Oon $\mathrm{V}$, Thomas P. Outcome of pregnancy in HIV-positive women planned for vaginal delivery under effective antiretroviral therapy. J Obstet Gynaecol. 2010;30(1):38-40.

157. Ong JJ, Chen M, Hocking J, Fairley CK, Carter R, Bulfone L, et al. Chlamydia screening for pregnant women aged 16-25 years attending an antenatal service: a cost-effectiveness study. BJOG. 2016;123(7):1194-202.

158. Ditkowsky J, Shah KH, Hammerschlag MR, Kohlhoff S, SmithNorowitz TA. Cost-benefit analysis of Chlamydia trachomatis screening in pregnant women in a high burden setting in the United States. BMC Infect Dis. 2017;17(1):155.

159. Hersh AR, Megli CJ, Caughey AB. Repeat screening for syphilis in the third trimester of pregnancy: a cost-effectiveness analysis. Obstet Gynecol. 2018;132(3):699-707.

160. Cohen DA, Wu S-Y, Farley TA. Comparing the cost-effectiveness of HIV prevention interventions. J Acquir Immune Defic Syndr. 2004;37(3):1404-14.

161. Lin F, Farnham PG, Shrestha RK, Mermin J, Sansom SL. Cost effectiveness of HIV prevention interventions in the U.S. Am J Prev Med 2016; 50(6):699-708.

162. Huang Y-LA, Lasry A, Hutchinson AB, Sansom SL. A systematic review on cost effectiveness of HIV prevention interventions in the United States. Appl Health Econ Health Policy 2015; 13(2):149-56.

163. Jacobsen MM, Walensky RP. Modeling and cost-effectiveness in HIV prevention. Curr HIV/AIDS Rep. 2016;13(1):64-75.

164. Holtgrave DR, Hall HI, Wehrmeyer L, Maulsby C. Costs, consequences and feasibility of strategies for achieving the goals of the National HIV/AIDS strategy in the United States: a closing window for success? AIDS Behav. 2012;16(6):1365-72. 
165. Brent RJ, Brennan M, Karpiak SE. Economic evaluations of HIV prevention in rich countries and the need to focus on the aging of the HIV-positive population. Curr Opin HIV AIDS. 2010;5(3):255-60.

166. John-Baptiste A, Yeung MW, Leung V, van der Velde G, Krahn M. Cost effectiveness of hepatitis C-related interventions targeting substance users and other high-risk groups: a systematic review. Pharmacoeconomics. 2012;30(11):1015-34.

167. Bernard CL, Owens DK, Goldhaber-Fiebert JD, Brandeau ML. Estimation of the cost-effectiveness of HIV prevention portfolios for people who inject drugs in the United States: A model-based analysis. PLoS Med. 2017;14(5):e1002312.

168. Selvapatt N, Ward T, Harrison L, Lombardini J, Thursz M, McEwan P, et al. The cost impact of outreach testing and treatment for hepatitis $\mathrm{C}$ in an urban Drug Treatment Unit. Liver Int. 2017;37(3):345-53.

169. Tuli K, Kerndt PR. Preventing sexually transmitted infections among incarcerated men who have sex with men: a cost-effectiveness analysis. Sex Transm Dis. 2009;36(2 Suppl):S41-8.

170. Barham L, Lewis D, Latimer N. One to one interventions to reduce sexually transmitted infections and under the age of 18 conceptions: a systematic review of the economic evaluations. Sex Transm Infect. 2007;83(6):441-6.

171. Baral SD, Poteat T, Strömdahl S, Wirtz AL, Guadamuz TE, Beyrer C. Worldwide burden of HIV in transgender women: a systematic review and meta-analysis. Lancet Infect Dis. 2013;13(3):214-22.

Publisher's Note Springer Nature remains neutral with regard to jurisdictional claims in published maps and institutional affiliations. 